\title{
SYMPOSIUM ON CONGENITAL HEART DISEASE
}

As part of the commemoration of the Centenary of the National Heart Hospital, the Institute of Cardiology arranged a symposium on some aspects of congenital heart disease. The subjects chosen were limited to specific problems of current interest, and the opening speakers were asked to limit their remarks to these, without making any attempt to cover the subject as a whole.

The meeting was held at the Ciba Foundation, Portland Place, on Thursday, October 3, 1957. Mr. Wolstenholme, the Director of the Ciba Foundation, said how pleased they were to be able to provide facilities for the meeting. Maurice Campbell thanked him and the Foundation for their hospitality and welcomed the visitors who had been invited to take part in the discussion.

\section{FIRST SESSION CHAIRMAN: MAURICE CAMPBELL}

Coarctation of the Aorta. The Causes of Heart failure in Infancy and the Relationship to Fibro-Elastosis

OPENED BY R. E. BONHAM-CARTER

Coarctation of the aorta of the adult type presenting as the main lesion accounts for about 4 per cent of all congenital heart lesions at Great Ormond Street. It accounts for 4 per cent of the deaths in the necropsy series. Two-thirds of the deaths from these malformations occur under the age of six months. We have no evidence that coarctation results in heart failure more frequently than other surgically correctable lesions in early infancy.

There are three main reasons why infants with congenital heart disease die so young. The first is their relative lack of immunity to respiratory infection and these tip them over into failure: their inherited immunity declines in the first six months, the measurable decline being in $\gamma$ globulin and diphtheria anti-toxin levels. The second is the normal depletion of their iron store; this is more obvious in the polycythæmic cyanotic patients, who need to make so many red cells for oxygen transport, but occurs in the acyanotic group also and gives rise to an anæmic anoxia of the myocardium. Clearly, the third reason is the severity of the lesion.

In our series we have a higher proportion of patients complicated by a patent ductus $(25 \%)$ than would be expected from the published figures $(10 \%)$. The patency of the duct may delay the essential development of the collateral circulation. Four years ago by doing left auricular biopsy in these and other infants we thought we had found a high proportion with endocardial fibro-elastosis. Reassessment of these biopsies and the post-mortem specimens has shown us that this thickened endocardium is a stress phenomenon and does not indicate the more generalized disease. Serious fibro-elastosis of the left heart is so rare in these infants that the possibility of its presence should not deter anyone from advising resection.

C. G. Parsons. An analysis of 50 cases of coarctation presenting during the first year of life did not suggest that fibro-elastosis was an important factor. The coarctation was post-ductal in 11, of whom 6 survived, and preductal in 39 of whom 38 died; only one had a closed ductus arteriosus. Pneumonia was common and might have been responsible for some deaths but heart failure was usual. Strain on the right ventricle was increased because it was forced to work against a systemic pressure, the ductus being open in all but one infant. Further, there were indications that the pulmonary circulation was abnormal, often with X-ray evidence of pulmonary vascular congestion. Dr. Cameron had found thickening of the media and prominent internal and external elastic laminæ more often in these cases than in normal controls. 
R. M. Marquis. In nine cases of coarctation coming to autopsy in the Edinburgh Children's Hospital, endocardial fibro-elastosis has been so common and so variable that we have reached the conclusion that, even when obvious $\mathrm{T}$ wave changes are present, it should be ignored in assessing such an infant for surgical treatment.

J. D. Hay. Of nine infants with coarctation, four died, and in none of these was endocardial fibroelastosis found.

D. J. Waterston. Fibro-elastosis is a post-mortem diagnosis that need not be considered in assessing patients with coarctation for surgery.

$R$. H. Hudson. Some degree of fibro-elastosis is common in all hearts at autopsy and the condition may be due to organization of blood clot.

$R$. E. Bonham-Carter (in reply). The decision to operate on coarctation of the aorta in infancy depends on the skill of the surgical team. With increasing experience more cases will come to surgery in infancy. At present in my experience the mortality of medical and surgical treatment in infancy is about the same.

\section{CoARCtATION: Complications OF RESECTION}

Opened BY Graham HaYward

I propose to discuss the vascular lesions found in association with coarctation of the aorta, as these may be important both in the selection of cases for surgical treatment and as a cause of postoperative complications. Some patients, following resection of the coarctation, have attacks of abdominal pain, sometimes associated with vomiting or signs of intestinal obstruction. These symptoms have been shown to be due to an acute arteriolar necrosis, histologically identical with the picture of polyarteritis nodosa. In a recent case laparotomy showed widespread miliary aneurysms, one of which had ruptured and caused massive intraperitoneal hæmorrhage, and another had thrombosed and caused gangrene of a part of the small bowel: episodes of abdominal pain and intestinal obstruction continued to occur for several months after operation. The arteriolar necrosis is said to be caused by the sudden rise in pressure in vessels below the level of the coarctation, and although the lesions seem to subside after a period of time, there may be a place for the use of corticosteroids to prevent the complications of hæmorrhage or thrombosis.

Two of the common causes of death in coarctation are rupture of the aorta due to dissecting aneurysm and intracranial hæmorrhage from rupture of a congenital intracranial aneurysm. Generally, these complications are not associated with an excessively high blood pressure proximal to the coarctation, and one of the sites where dissection may occur is just distal to the coarctation. Histologically there is evidence of medial necrosis of the aorta with arteriolar lesions. Although the dissection is usually fatal, a history of episodes of acute retrosternal pain with radiological evidence of unusual dilatation of the aorta suggests that some healing can occur. In such cases operation may be difficult because of the thin and friable aortic wall.

It is suggested that in patients with coarctation of the aorta there may be a widespread abnormality of the small arteries and that this may be responsible for some of the complications that occur before and after operation.

J.F. Goodwin. In one case of abdominal pain after resection of a coarctation, there was either hæmorrhagic ascites or perforation, presumably associated with arterial lesions in the mesenteric vessels. This may be due to a sudden increase of blood flow to the splanchnic area. In another case an aneurysm developed at the site of resection with disastrous results.

D. J. Waterston. It might be useful to examine the resected specimens histologically as a routine for evidence of medial necrosis.

C. G. Parsons. We have some evidence that the aortic wall is always abnormal in uncomplicated coarctation. This is provided by K. W. Donald and S. Taylor, who demonstrated that the response of the pulse pressure to exercise is abnormal both before and after satisfactory resection. A complication of another kind, observed on three occasions, is recurrence of the coarctation after apparently successful operation. 


\section{Subaortic Stenosis: Diagnosis and TREATMent}

OPENED BY R. M. MARQUIS

There have been many misconceptions about the frequency, anatomical variations, and clinical features of subaortic stenosis. Surgical experience, by revealing cases that might otherwise have gone unrecognized, has suggested that subaortic stenosis is less uncommon than had been supposed recently, and that it is commonly isolated and may be as severe as valvular stenosis. Moreover, a few cases have been treated surgically with success, so that its accurate diagnosis and assessment is important.

Precision of diagnosis depends on the distinction of subaortic from valvular stenosis. At the present time an absolute distinction depends on (1) direct vision of the subaortic lesion at autopsy or (2) direct vision of a normal aortic valve at open operation for known aortic stenosis. Blind transventricular aortic valvotomy may not distinguish subaortic from valvular stenosis, but possibly intra-aortic palpation of a normal aortic valve in the presence of proved aortic stenosis may prove reliable evidence.

Circumstantial evidence for the diagnosis of subaortic stenosis may be obtained by (1) catheter withdrawal tracings from aorta to left ventricle, and possibly by (2) angiocardiography, but it may prove necessary to inject the contrast medium direct into the left ventricle to obtain sufficient clarity of definition in the subaortic region. The site and distribution of the systolic murmur, the quality of the aortic second sound, the shape of the cardiovascular shadow, and the presence or absence of post-stenotic dilatation of the ascending aorta, when correlated with a confirmed diagnosis of subaortic stenosis, may eventually prove of real help.

Treatment. Severe cases require full assessment for surgical relief of the obstruction. At present this is based on experience of aortic valvotomy in general: in future it must depend on an analysis of the results obtained in subaortic stenosis. This distinction is essential, for it should prove possible to relieve subaortic obstruction without the production of aortic regurgitation. The results of operation may, therefore, be more predictable than they are in valvular stenosis and operation may be justified earlier in the course of the disease.

These two slides (not reproduced here), which show the heart from a 12-year-old girl with subaortic stenosis, demonstrate the massive left ventricular hypertrophy that may result from this lesion in a severe form, and the risk of blind transventricular dilatation of a subaortic obstruction, for in breaking down the obstruction, the ventricular wall was torn and the tear extended into the aorta causing partial detachment of one of the aortic cusps.

Clarity in the discussion would probably be best achieved if directed to (1) circumstantial evidence of the diagnosis based on the findings in proved cases of subaortic stenosis, and to (2) the results of operation in proved subaortic stenosis.

If we are able to muster sufficient information within these limits, it should be possible to establish criteria by which a diagnosis of subaortic stenosis can be reached without resort to thoracotomy, to obtain an indication of what may be expected from this type of aortic surgery, and to pave the way to recognition of the true frequency of this form of congenital aortic stenosis.

M. Campbell. Dilatation of the first part of the aorta is suggestive but not decisive of valvular stenosis. In 13 necropsies of congenital aortic stenosis (7 children and 4 adults) only 1 was subvalvular $(7 \%)$, and in 84 cases of isolated aortic stenosis operated on by Sir Russell Brock $5(6 \%)$ were thought to be subvalvular. Unfortunately, aortic regurgitation may sometimes follow an operation for subvalvular stenosis.

$P$. Wood. In my series of 9 proved cases of congenital aortic stenosis 4 were subvalvular. Aortic regurgitation is common in both types. In some cases of valve stenosis there may also be infundibular stenosis -a situation with which we are only too familiar in pulmonary stenosis.

$W$. Somerville. Angiocardiography may help to identify stenosis of the left ventricular outflow tract, if (1) the contrast medium is injected rapidly through a wide-bore catheter into the right atrium or preferably the right ventricle, (2) the pictures are taken in the left lateral position, and (3) the exposures are rapid and numerous enough to show both systole and diastole of the left ventricle. 
L. McDonald. I have seen a necropsy at which valvular and true infundibular stenosis co-existed. Such cases may be overlooked if pressure gradients are taken from above and below the valve region, without withdrawal tracings. The latter are, in themselves, often difficult to interpret.

$R$. V. Gibson. It may be difficult to recognize the level of stenosis even on withdrawal tracings across the aortic valve during left-heart catheterization. The subvalvular stenosis may be so close to the valve that it cannot be identified. The absence of calcification of the aortic valve in a patient over the age of 30 is a point in favour of subaortic stenosis. I have seen a case in which there was functional subvalvular stenosis associated with hypertension, with a pressure gradient approaching $100 \mathrm{~mm}$. $\mathrm{Hg}$ : necropsy showed a normal aortic valve and gross hypertrophy and functional stenosis of the left ventricular outflow tract.

R. M. Marquis (in reply). It would be convenient if post-stenotic dilatation of the ascending aorta were confined to valvular stenosis, but this is suggestive rather than reliable, as it is in pulmonary stenosis. I have no evidence that muscular hypertrophy itself leads to obstruction of the left ventricular outflow tract as it appears to do on the right side in some cases of pulmonary stenosis. Angiocardiography by selective pressure injection through a Lehman catheter into the right ventricle has not always given clear definition, even in the lateral position, but my experience is restricted to apparatus that allows only two films a second.

Valvular and subaortic stenosis may co-exist and calcification may affect the subaortic as well as the valvular lesion. Even so, it is an attractive suggestion that the absence of calcification in patients over 30 favours subaortic stenosis. It is clear from this discussion that there is still much to be learnt about subaortic stenosis. Left-heart catheterization, left-heart angiocardiography, and further surgical endeavour are likely to play the major roles in increasing our knowledge of this relatively uncommon malformation.

\section{The Diagnosis of Mitral Stenosis in the Presence of Atrial Septal Defect}

OPENED BY J. W. BROWN

The association of mitral stenosis and atrial septal defect (A.S.D.) is by no means as common as some have thought. It might be reasonable to expect that in cases of A.S.D. the mitral valve would be hypoplastic for the same reason as the aorta, but there is no confirmation of this in specimens examined. Whether there is a rheumatic history or not, the mitral stenosis is of rheumatic type and the valve has not the appearance that is seen, for example, in the mitral stenosis associated with coarctation. Perhaps 5 per cent or less of cases of A.S.D. have mitral stenosis. A Lutembacher syndrome has not been seen in a child, nor is congenital mitral stenosis particularly associated with an A.S.D.

In the past, more often than not, a diagnosis of Lutembacher's syndrome has been based on a diastolic murmur at the apex and this is bound to be unreliable, for at least a fifth of the cases of acyanotic congenital heart disease have such a murmur in the absence of mitral valvular disease. This diastolic murmur can be explained in a variety of ways and its timing is usually mid-diastolic. In A.S.D. it may perhaps be created at the septal defect itself for the defect is a diaphragm-like orifice intervening between the left and right atria. There are, of course, a number of cases of A.S.D. with mitral stenosis that have all the hall marks of mitral stenosis-a loud first sound, opening snap, and diastolic rumble with presystolic accentuation-and it is the large heart and dilated pulmonary vessels in these cases of apparently true mitral stenosis, often with a paucity of symptoms, that leads to catheter and other investigations to look for the septal defect. On these grounds any clinical series of cases of A.S.D. will always include a very few with mitral stenosis. Unfortunately, in many cases the stethoscopic signs of mitral stenosis may be absent because of the large shunt passing from left to right through the defect and bypassing the valve.

What have conventional methods of examination to offer us as a help in diagnosis? With or without mitral stenosis, an A.S.D. shows in radioscopy a large heart with hypertrophy and dilatation of the right chambers and dilated pulmonary arteries. Excessive pulsation of the pulmonary arteries, not always a hilar dance, is very suggestive of an A.S.D. and helps to differentiate it from mitral stenosis with pulmonary hypertension. In A.S.D. with mitral stenosis the left atrial curve may be slightly increased as part of the general enlargement of the heart, and in some cases there may be obvious left atrial enlargement: in others the left atrium is not enlarged at all. The right 
atrium usually shows great enlargement. The electrocardiogram tells us nothing about the presence of mitral stenosis, and the $\mathbf{P}$ waves are not always bifid. I think that auricular fibrillation in the thirties with a raised jugular venous pressure in a case with cardiac configuration of A.S.D. is very suggestive of the presence of mitral stenosis. It is stated that mitral stenosis emphasizes every clinical and anatomical change produced by an A.S.D.: it may do so in some cases but not always.

When confronted with an average case that comes labelled as Lutembacher's syndrome from radiological findings, it is most likely to turn out to be mitral stenosis with pulmonary hypertension, or A.S.D. alone. The age group usually seen is from 30-70. If the monomarks of mitral stenosis are present, that is the probable diagnosis. If radioscopy shows increased hilar pulsation, then catheter examination may prove the presence of an A.S.D. It rarely proves the presence of mitral stenosis, but the only sure proof of this is a pressure gradient across the mitral valve or palpation of the valve at the time of repair of a septal defect.

P. Wood. In my experience of 400 operations for mitral stenosis only one patient was found to have an A.S.D.: conversely, in 50 operations for A.S.D., only one (2\%) had mitral stenosis-a percentage similar to that in the general population. The combination of a large A.S.D. and severe mitral stenosis is, I think, incompatible with life. Has anyone seen such a case? It is easy to estimate the size of the mitral orifice in cases with A.S.D. because the left atrial pressure can be measured by direct inspection of the neck veins. If the cardiac output is over 3 litres a minute and the jugular venous pressure less than $3 \mathrm{~cm}$., there can be no mitral stenosis. All patients with Lutembacher's syndrome have a raised jugular venous pressure, the left and right atrial pressures being about the same, but it is difficult to distinguish between mitral stenosis and a raised left ventricular diastolic pressure as a cause of this (A.S.D. with high venous pressure).

L. McDonald. A gradient across the mitral valve may be caused by mitral regurgitation as well as by stenosis.

J. F. Goodwin. Calcification of the mitral valve is a useful sign in a patient with an A.S.D., but I agree that this does not necessarily mean stenosis.

A. Leatham. The possibility of distinguishing between mitral and tricuspid diastolic murmurs by phonocardiography should not be forgotten.

$W$. Somerville. Of 50 cases of A.S.D. treated surgically at the Middlesex Hospital 3 had mild mitral stenosis, the valve admitting about one and a half fingers $(2.5 \mathrm{~cm}$.). All three were fibrillating, had a raised venous pressure, a large heart (cardiothoracic ratio over $70 \%$ ) and a normal pulmonary vascular resistance. In retrospect, there was no feature that would have allowed a confident diagnosis of mitral stenosis before operation.

\section{Atrial Septal Defect: Reversed Shunt with Normal Pulmonary Vascular RESISTANCE}

OPENED BY WALTER SOMERVILle

This is an uncommon condition characterized by three main features: viz. (1) atrial septal defect (A.S.D.), (2) central cyanosis, and (3) absence of any of the established causes of cyanosis in A.S.D., namely, $(a)$ raised pulmonary vascular resistance, $(b)$ pulmonary stenosis, $(c)$ superior or inferior vena cava entering left atrium, $(d)$ pulmonary artery thrombosis, or $(e)$ tricuspid stenosis.

Three such patients have been seen at the Middlesex Hospital since 1950, two girls aged 10 and 12 , and a boy aged 4 years. In two of them auscultatory and phonocardiographic signs suggested A.S.D. and the cardiogram showed right bundle-branch block, but slight cyanosis was present at rest and increased with exercise: in the third the pulmonary second sound was not heard. Cardiac catheterization showed a left-to-right shunt at atrial level in all three and the left atrium 
was entered with ease. Right ventricular and pulmonary arterial pressures and pulmonary vascular resistances were normal. Arterial oxygen saturations were 80-85 per cent at rest. Angiocardiograms were carried out via the inferior vena cava in two patients and in one of them, via the superior vena cava as well, without explaining the cyanosis.

A possible explanation is increased resistance to right ventricular filling from impaired distensibility due to an endocardial or myocardial factor, for example, fibro-elastosis of the right ventricle. However, pressure curves from right atrium and ventricle do not demonstrate any difficulty in right ventricular diastolic relaxation.

P. Wood. In a further three cases, in spite of right bundle-branch block, the second sound was single or normal, unlike Somerville's cases where it was widely split and fixed. I do not think the cyanosis is due to a low defect for it has been absent in many such cases proved surgically. A similar physiological situation occurs when A.S.D. is associated with either Ebstein's disease or gross pulmonary regurgitation secondary to idiopathic dilatation of the pulmonary artery.

R. V. Gibson. If the A.S.D was closed, the subsequent physiological findings might help to solve the problem.

P. Wood. In a case somewhat similar but with cyanosis developing later, in which the A.S.D. was closed, there was found to be free tricuspid regurgitation and this increased and the jugular venous pressure rose after closure of the A.S.D.

$W$. Brigden. The cyanosis might be due to left ventricular disease causing a modified Bernheim effect.

J. F. Goodwin. The A.S.D might be high, giving perferential shunting from superior vena cava into left atrium.

M. B. Mcllroy. Using ear oximetry it can be shown that a number of cases of A.S.D. desaturate on exercise: this might support the theory of preferential shunting.

R. E. Bonham-Carter. A likely explanation is that the A.S.D. is associated with Ebstein's disease, as in pædiatric practice varying degrees of Ebstein's disease are not uncommon.

$W$. Evans. In the second case the right ventricular hypertrophy together with right bundle-branch block suggests that there might have been some pulmonary hypertension in spite of the pressures recorded at catheterization. The opener did not agree.

A. Leatham. Could the cyanosis be caused by an abnormally low end-diastolic left ventricular pressure?

$W$. Somerville (in reply). Surgery had been considered in one of our cases but so far has not been done. The possibility of an associated Bernheim effect has been thought of but there was no evidence of left ventricular disease. The possibility of a high A.S.D. accounting for the cyanosis is unlikely as many such cases, confirmed surgically and at necropsy, have been free from cyanosis.

\section{The Cause of the Respiratory Fixation of a Split Second Sound}

\section{OPENED BY AUBREy LEATHAM}

Wood drew attention to obvious splitting of the second heart sound as a physical sign of atrial septal defect (Barber et al., 1950). Phonocardiograms at the London Hospital showed that aortic closure was first and was separated from pulmonary closure by an interval of 0.04 to $0.05 \mathrm{sec}$. This was no greater than the normal interval during the inspiratory phase of respiration; the abnormality lay in the persistence of the splitting in the expiratory phase of respiration, the split decreasing only very slightly during expiration.

At first this was attributed to delay in onset of electrical activation of the right ventricle as suggested by the rSR' complex in the electrocardiogram. No delay, however, was found in the onset of the right ventricular pressure pulse (Leatham and Gray, 1956). Prolongation of electrical activation of the right ventricle was a possible cause, but no abnormality of splitting of the second sound was found in patients with a similar electrocardiogram, but without an A.S.D. Selective increase in right ventricular stroke volume (compared with the left, because of the left-to-right shunt) has been thought the most likely cause for the wide splitting of the second sound. A further increase in right ventricular stroke volume on inspiration (as in normal subjects) was perhaps impossible or greatly reduced, so that little further delay in pulmonary closure occurred on inspiration, 
thus accounting for the respiratory fixation. The wide fixed splitting was found with high pulmonary vascular resistan ce also, provided that the left-to-right shunt continued, but was absent when there was a right-to-left shunt that reduced the right ventricular stroke volume. Finally, the abnormal splitting was found to disappear in a few patients in whom the defect had been closed, even when the electrocardiogram was unaltered.

Further experience, however, with the increasing numbers of patients whose defects have now been closed shows that there may be a delay in return of the second sound to normal of several weeks or longer following the operation (Blount, 1954; Wood and Somerville, both personal communications). This challenges the concept of selective increase in right ventricular stroke volume as the cause of the abnormal second sound, and suggests that it may be due to changes in pulmonary vascular resistance. Since the greatly increased flow in uncomplicated A.S.D. is accompanied by normal pressures there must be a decrease in pulmonary vascular resistance. Jonsson (personal communication) points out that the dicrotic incisura is then low down on the descending limb of the pulmonary artery pulse wave, and thus pulmonary closure is late. With a high pulmonary vascular resistance the incisura is situated high up on the descending limb and pulmonary closure is early. There appear to be exceptions to this rule and further study is required, particularly of changes in pulmonary vascular resistance with respiration and their relation to splitting of the second sound.

$W$. Somerville. The split has been fixed in 70 per cent of the first 50 cases of A.S.D. in which the defect has been closed at the Middlesex Hospital. In a number of these the delay in the pulmonary second sound persisted a year after successful closure of the defect, as proved by 'catheterization. In nearly all these, the pulmonary resistance was under one unit.

J. Shillingford. Have any observations been made on the behaviour of the aortic second sound after the administration of various drugs that might lower the peripheral resistance?

R. Gibson. In 40 cases of A.S.D. only one had a normally split second sound before operation: there was systemic hypertension and after closure of the defect the split became reversed. In A.S.D. inspiration affects right and left ventricular filling equally, therefore it would be unlikely for the split to widen during this phase of respiration, and the fixed split is not incompatible with the hypothesis that the delay in the pulmonary second sound is caused by increased stroke volume of the right ventricle.

R. E. Bonham-Carter. The pulmonary second sound does in fact move a little with respiration in most cases, especially in children. To this Leatham agreed saying it amounted only to $0.01 \mathrm{sec}$.

$P$. Wood. I am surprised at Somerville's finding concerning the behaviour of the second heart sound after closure of the defect: in 14 of the last 15 cases in which the defect has been closed the split had become normal 5 to 10 days after operation - the average time being 7 days. The delay in the pulmonary second sound is due to increased stroke volume of the right ventricle, and probably the right ventricular filling resistance may return to normal slowly after operation. During this post-operative phase the split is fixed when the patient is lying, but on sitting, which lowers the venous pressure, the split becomes normal. If this view is correct, the cardiac output should be raised in the immediate post-operative period, a point that is under investigation.

A. Leatham (in reply). I agree with Wood and think the most likely hypothesis is that the delay in the pulmonary second sound is caused by over-filling of the right ventricle.

\section{The Cause of the Continued Left-to-Right Shunt in A.S.D. When the Right Atrial PRESSURE IS High}

OPENED BY RONALD GiBson

In most cases of A.S.D. with a low or moderately raised pulmonary vascular resistance the shunt continues to be wholly or predominantly left-to-right when the right atrial pressure is high: the left atrial pressure remains as high or higher than the right. It follows that, despite the high atrial pressures, the right ventricle must still offer a lower resistance to filling than the left, as is usual in uncomplicated A.S.D. Therefore, the crucial question is what is the mechanism whereby, in the presence of a high atrial pressure, the left ventricle maintains its normal higher resistance to filling? 
Three different mechanisms have been postulated: (1) left ventricular filling is limited by tension due to a stretched pericardium, (2) the high atrial pressure is due to left ventricular failure or malfunction of the left ventricle, or (3) left ventricular filling is impaired because the inter-ventricular septum is bulging into the cavity of the left ventricle (reversed Bernheim's syndrome).

(1) The pericardium does not seem to play any part in limiting left ventricular filling, since it is not tense at operation, the heart does not herniate through the incised pericardium, and the leftto-right shunt continues after the pericardium has been opened widely. (2) The evidence that the high atrial pressure is due to left ventricular failure is unconvincing for the alleged failure is attributed to mitral regurgitation or systemic hypertension of a degree that would not ordinarily cause failure. (3) The concept of impaired left ventricular filling due to bulging of the septum to the left is interesting but difficult to prove. None of these mechanisms offers a wholly satisfactory explanation for the continued left-to-right shunt, although the reversed Bernheim's syndrome is the least objectionable.

The high atrial pressure is a manifestation of right ventricular failure, and the continued left-toright shunt is due to the right ventricle in failure remaining more readily distensible than a normal left ventricle (if the left ventricle can be regarded as normal in A.S.D.). The different atrial and ventricular end-diastolic pressure levels in right and left heart failure offer some support for this view. In right ventricular failure from any cause they are usually $10-15 \mathrm{~mm}$. $\mathrm{Hg}$ (identical with the pressures found in the type of A.S.D. under consideration). By contrast, in left ventricular failure they are usually much higher at $30-40 \mathrm{~mm}$. (personal observations at thoracotomy in eight cases, seven with aortic stenosis and one with ischæmic heart disease, all of which were in left ventricular failure at the time). The level of the atrial or ventricular end-diastolic pressure in this type of A.S.D. would not be high enough to influence materially left ventricular filling and the right ventricle would remain more readily distensible than the left, even though the former is in a state of failure. If this were so then clearly the shunt would continue to be wholly or predominantly left-to-right despite the high right atrial pressure.

W. P. Cleland. The pericardium at operation is always slack in these cases and never constricting.

J. Shillingford. Left ventricular end-diastolic pressure in failure is surprisingly high, $20 \mathrm{~mm}$. $\mathrm{Hg}$ at rest and $30-40 \mathrm{~mm}$. on exercise.

L. McDonald. There is no need for it to be raised to the levels found with clinical heart failure: smaller increases might indicate ventricular dysfunction.

P. Wood. In 22 cases of A.S.D. with raised jugular venous pressure, a left-sided lesion or increased output has been found in 19 (11 had hypertension with a diastolic pressure over $120 \mathrm{~mm}$. $\mathrm{Hg}, 5$ had mitral valve disease, 2 were thyrotoxic, and 1 severely anæmic): this, however, does not explain the 3 others. But essentially these findings support the views of Dexter (1956).

M. B. McIlroy. If the venous pressure is reduced by tipping the patient, there is difficulty in left ventricular filling, manifested by a fall in systemic pulse pressure.

$R$. E. Bonham-Carter. V.S.D. is a common cause of failure in infancy and in these cases the shunt remains left-to-right: this supports the view that ventricular filling is at fault:

$R$. Gibson (in reply). I disagree with the theory that a left-sided lesion is important. I have seen a case where the venous pressure had been raised for 7 years, and if this was due to left ventricular failure the patient would have been unlikely to survive so long.

$P$. Wood. The problem is largely a matter of nomenclature: the filling resistance to the left ventricle is raised, but the cause for this is still uncertain.

\section{The Significance of a Pressure Gradient across the Pulmonary Valve in A.S.D.}

\section{OPENED BY LAWSON MCDONALD}

Interest in the significance of the systolic pressure gradient across the pulmonary valve which occurs not uncommonly in A.S.D., has heightened with the now excellent results of operative repair of this defect. There are several important questions. Firstly, whether the gradient indicates true pulmonary stenosis, and if so, whether it is ever severe enough to merit valvotomy at 
the time of repair of the A.S.D. Secondly whether the pressure gradient may be produced by some other mechanism than pulmonary stenosis, possibly involving the increased pulmonary blood flow, such as $(a)$ disproportion between a pulmonary valve of normal area and increased blood flow through it, $(b)$ disproportion between an abnormally large right ventricle and a relatively normal valve ring, $(c)$ suction effect on the catheter tip, or $(d)$ functional obstructions occurring in the outflow tract of the right ventricle, or a combination of such mechanisms.

With these points in view I have analysed the hæmodynamic findings on 50 consecutive cases of A.S.D., all ostium secundum defects; a large number have already had the defect repaired by Sir Russell Brock. In Fig. 1 the pulmonary systemic flow ratio (pulmonary flow divided by systemic

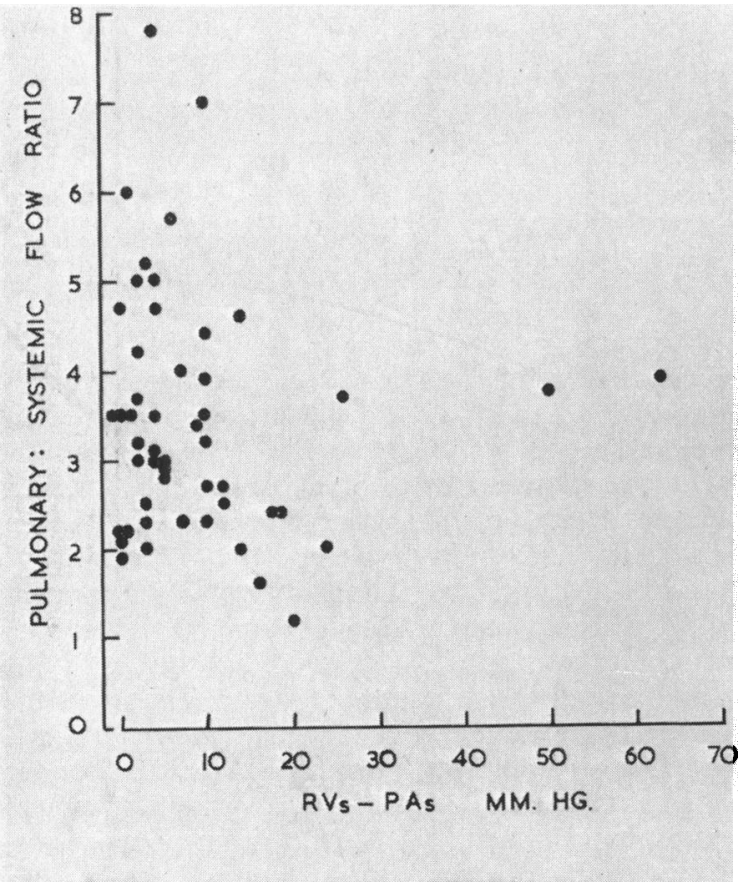

FIG. 1.-The relationship of the pulmonary/systemic flow ratio (pulmonary flow in $1 . / \mathrm{min}$. divided by systemic flow in $1 . / \mathrm{min}$.) and the pulmonary systolic gradient (right ventricular systolic pressure minus pulmonary arterial systolic pressure in $\mathrm{mm}$. $\mathrm{Hg}$ ) in atrial septal defect. See text.

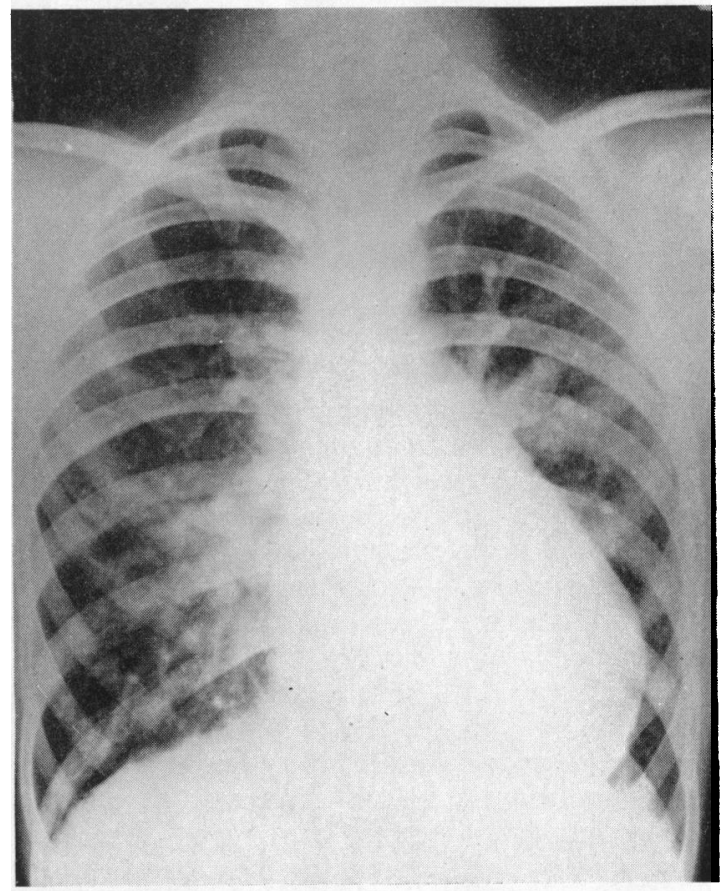

FIG. 2.-X-ray of the chest in a patient with atrial septal defect and a pulmonary systolic gradient of more than $60 \mathrm{~mm}$. See text.

flow, both in $1 . / \mathrm{min}$.) is related to the systolic gradient across the pulmonary valve (RV-PA in mm. $\mathrm{Hg}$ ). The error in estimating pulmonary blood flow by the Fick principle, in the presence of leftto-right shunts, is of course well-recognized. But even taking this into account, the highest gradients (including one of $63 \mathrm{~mm}$. and another of $50 \mathrm{~mm}$.) occurred not in the cases with the greatest pulmonary flows, but in those with only moderately increased flows (pulmonary systemic flow ratios of $3-4 / 1$ ). This suggests that the magnitude of pulmonary blood flow, although it may affect the systolic gradient, is not the main factor in determining it. Alternatively, some degree of pulmonary stenosis may prevent the extreme increases of pulmonary blood flow in A.S.D. But in pulmonary stenosis with an intact septum needing valvotomy, the pulmonary arterial mean pressure is not well maintained, and the arterio-venous oxygen difference becomes exaggerated. 
Fortunately operative findings illuminate the problem. It is already proven that these systolic pressure gradients across the pulmonary valve in A.S.D. may disappear after closure of the defect. This occurred in the patient with the gradient of $63 \mathrm{~mm}$., and Blount of Denver has written to me of a patient with atrial septal defect and a systolic gradient of $78 \mathrm{~mm}$. across the pulmonary valve, which was found to be zero at catheterization after operative repair of the defect. This is an extreme example of a type of case of which we have growing experience, where even a towering gradient is unaccompanied by pulmonary stenosis, and therefore indicates the unreliability of the gradient as a sole guide. Sir Russell Brock tells me that, although he has closed an A.S.D. during an operation performed for pulmonary stenosis, he has never found pulmonary stenosis that he considered in need of valvotomy, at the time of operation undertaken for the repair of A.S.D. I am aware that all surgeons will not concur with this.

It seems, in conclusion, that pulmonary stenosis requiring surgical relief is unlikely, or possibly even incompatible, with the hæmodynamic changes occurring in A.S.D. cases needing repair. Fig. 2 shows the X-ray of the chest of a patient with a pulmonary systolic gradient of more than $60 \mathrm{~mm}$.: it is hard to conceive that the pulmonary valve is in any way damming back the flow of blood into such plethoric lungs. This is not so say that the pulmonary valve is necessarily normal with A.S.D., but that any apparent obstruction at the pulmonary valve should perhaps best be reassessed after operation, as I believe that even if any true stenosis is present it will seldom, if ever, merit surgical correction in these cases.

M. B. McIlroy. I have been able to record a gradient at two different heart rates: with sinus rhythm of 95 a minute the gradient was $38 \mathrm{~mm}$. and with flutter at 130 it fell to $25 \mathrm{~mm}$. Hg. The stroke volume had fallen from $270 \mathrm{ml}$. with sinus rhythm to $170 \mathrm{ml}$. with flutter.

P. Wood. I agree with McDonald that there is no direct relationship between the flow and the gradient (slide shown). Some of the gradient is artifactual as it can not always be confirmed at operation, or when the pulmonary arterial pressure is checked by wedging the catheter in a pulmonary vein.

$W$. Somerville. A pressure gradient (range: $3-26 \mathrm{~mm}$. $\mathrm{Hg}$ ) across the pulmonary valve was present in half of our first 50 cases where an A.S.D. was closed. No correlation was found between the size of the gradient and the pulmonary flow, the left-to-right shunt, or the heart size.

M. Campbell. I have seen 16 patients with A.S.D. and a gradient of more than $20 \mathrm{~mm}$. $\mathrm{Hg}$ across the pulmonary valve. (1) 10 had large shunts up to 14 litres and gradients between 20 and $40 \mathrm{~mm}$. (2) 3 had similar shunts and gradients between 70 and $90 \mathrm{~mm}$. (3) The last 3 are hardly pertinent as they had similar large gradients but shunts of about 1 litre a minute that may become reversed. The smallest gradient where pulmonary stenosis was proved at necropsy was $35 \mathrm{~mm}$. in a case of V.S.D. Though moderatesized gradients may be due to a Venturi effect, we think that gradients of more than 35 , or perhaps $45 \mathrm{~mm}$., generally indicate slight stenosis or some narrowing in a dilated tract; and that if the flow is normal or only slightly increased, even smaller gradients such as $20 \mathrm{~mm}$. may indicate slight stenosis (see Brotmacher and Campbell, 1958).

$W$. Brigden. The answer could probably be supplied by a hydrodynamic physicist.

J. Shillingford. Recent work from our laboratory by Hoffman showed that, with a large pulmonary artery and no stenosis, the Venturi effect alone could account for a gradient of $15-20 \mathrm{~mm}$. Another factor is the angle of the aperture in the catheter to the flow, and to a lesser extent the site of the aperture in the catheter, i.e. tip or side. With a flow of 5 litres there might be a 5-10 mm. gradient and this gradient increases by the square of the rise in the flow.

J. F. Goodwin. Why is a gradient not found in all cases?

L. McDonald (in reply). The "functional" gradient seems to be something peculiar to A.S.D. and similar gradients may not occur with V.S.D.

\section{The Diagnosis of Persistent Ostium Primum}

Opened by Patrick Mounsey

Recent advances in the surgical treatment of A.S.D. have made the differentiation of a persistent ostium primum from a persistent ostium secundum of importance. While defects of the ostium 
secundum type have been safely and successfully closed in many centres, closure of an ostium primum presents greater technical difficulties and requires a heart-lung machine.

It is important to define the pathological entity. The ostium primum lesion may be the only abnormality apart from a bifid anterior cusp of the mitral valve, or it may be associated with a single common atrio-ventricular (A-V) valve and a V.S.D., when the condition is known as a persistent atrio-ventricular canal. Intermediate between these two extremes many different gradations of lesions are met. As might be expected the prognosis is better for the least severe type of pathological abnormality.

A generic name is needed to describe all of these lesions and thus differentiate them clinically from the persistent ostium secundum, which has been estimated to be about ten times as common. The names that have been proposed are persistent ostium primum, persistent common (A-V) canal, endocardial cushion defects, and atrio-ventricularis communis. Some of these cover only one type in the group, but the important thing these names try to convey is the basic concept of a gradation of A-V canal defects, resulting from failure of fusion of the endocardial cushions and the septum primum.

The points on which a diagnosis of persistent ostium primum may be suspected clinically have been recently summarized by Blount et al. (1956), Brandenburg and DuShane (1956), Bedford et al. (1957), and Campbell and Missen (1957). They depend on the frequent association of regurgitation at one or both A-V valves, most frequently the mitral, on the presence of an associated V.S.D. in some patients, and on the large size of the left-to-right shunt usually present.

When there is neither regurgitation at the A-V valves nor an associated V.S.D., the persistent ostium primum is probably clinically indistinguishable from a persistent ostium secundum. Thus, on clinical examination the patient is found to have the physical signs of A.S.D.- a cardiac impulse of right ventricular type, a systolic murmur, and relatively fixed splitting of the pulmonary second sound in the pulmonary area-but in addition there may be a loud pan-systolic murmur and thrill at the apex or the left sternal edge. Radiological findings include right atrial and right ventricular enlargement, dilatation of the pulmonary artery and its main branches, and pulmonary plethora, all typical of a large A.S.D. of the ostium secundum type, but in some patients there is evidence of left ventricular enlargement also.

Catheterization may show evidence of a left-to-right shunt at low atrial levels or at both atrial and ventricular levels; further evidence of the site of the septal defect may be obtained by observation of the path taken by the catheter in passing from the right atrium into the left ventricle. The electrocardiogram may sometimes give a valuable diagnostic clue, since it often shows partial right bundlebranch block with left axis deviation (Toscano-Barbosa et al., 1956). Left ventricular preponderance, left bundle-branch block, and complete heart block have also been reported and it may be that the electrocardiographic pattern seen in persistent ostium primum is related to the nature and severity of the defect of the A-V canal present.

Other points that may suggest the presence of a persistent ostium primum in a patient with an A.S.D. are an unusual degree of cardiac enlargement in childhood, general physical underdevelopment and mongolism, pulmonary hypertension occurring before the age of 20 , and bacterial endocarditis, which is rare with the secundum type. Although patients with the most severe types of A-V canal defect die in infancy, those with a less extensive defect may live to 60 (Rokitansky, 1875) and a persistent ostium primum cannot therefore be excluded on age alone.

L. McDonald. These two slides demonstrate a point in catheterization that may help in the differentiation: in the primum defects the catheter may escape easily into the aorta, but not with secundum defect.

J. D. Hay. Fabricius of Copenhagen claims to be able to differentiate these two defects and measure the size of the defect by the range of free movement of the tip of the catheter when it has been looped in the right atrium before being passed through the defect. Has anyone found this useful?

$W$. Brigden. It is difficult to assess a pansystolic murmur in the presence of an A.S.D. What is the frequency of left ventricular changes in the electrocardiogram of this condition? 
A. Leatham. Two cases over 50 years of age with necropsy control had left axis deviation and a late secondary $\mathrm{R}$ in aVR.

$W$. Brigden. Similar changes may be seen in V.S.D.

$R$. $V$. Gibson. Left axis deviation is a constant finding, but mitral regurgitation may or may not be present, and the same applies to a shunt direct into the ventricles. Q waves in V5 and V6 may be misleading as they are seen in secundum defects also.

R.M. Marquis. A girl, aged 9, with ostium secundum and with necropsy control had left axis deviation: there was no systemic hypertension in this case, and the intensity of the signs led to a diagnosis of V.S.D.

L. McDonald. In recent work (Hamer, 1958) at the Institute of Cardiology, left axis deviation appeared almost as reliable a sign of ostium primum as the abnormal vectorcardiogram, but there were three cases without it.

J. D. Hay. The cardiographic changes may be less at birth and may develop with increasing years.

$P$. Wood. Keith described a number of cases in infants under two years old who had left axis deviation.

C. G. Parsons. I agree that these changes may develop later. Left axis deviation may signify a common A-V canal, and we have seen cases of ostium primum without it. When flow through the defect is reversed, a few of our cases suggest that angiocardiography may distinguish between these lesions: with an ostium secundum blood is directed towards the roof of the left atrium; with an ostium primum it passes in an explosive manner towards the posterior wall of the left atrium.

\section{Anomalous Pulmonary Venous Drainage}

OPENED BY Dr. J. F. GoOdWIN

I should like first to consider the diagnosis of partial anomalous venous drainage with A.S.D. The anomalous vein or veins may be visible on the plain X-ray, and the cardiac catheter may enter a vein from the right atrium, in which case the diagnosis presents no problem (Fig. 3). Brewer (1953) has suggested that the right pulmonary artery may be small in cases of right pulmonary veins draining into the right atrium, but this has not been my experience.
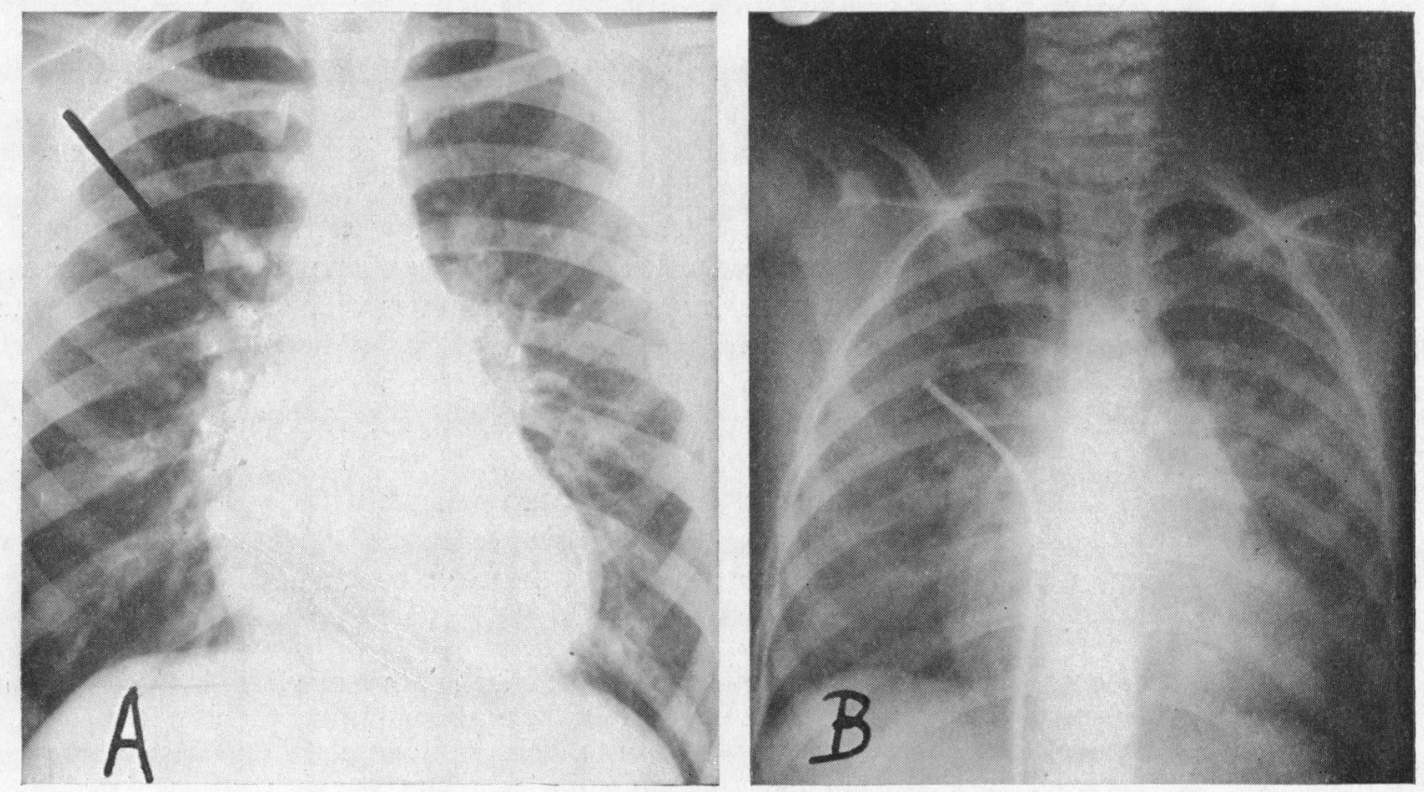

FIG. 3.-P-A tele-radiograph of a child with anomalous right pulmonary veins and atrial septal defect. (A) The upper anomalous vein (arrowed) can be seen as it enters the upper part of the right atrium. (B) Cardiac catheter entering the anomalous vein from the right atrium. 
Anomalous pulmonary veins, however, may enter the right atrium at an unusual site and be associated with anomalous caval drainage. In a personal case the right pulmonary veins entered the roof of the right atrium, and the inferior vena cava entered the left atrium (Fig. 4). This situa-

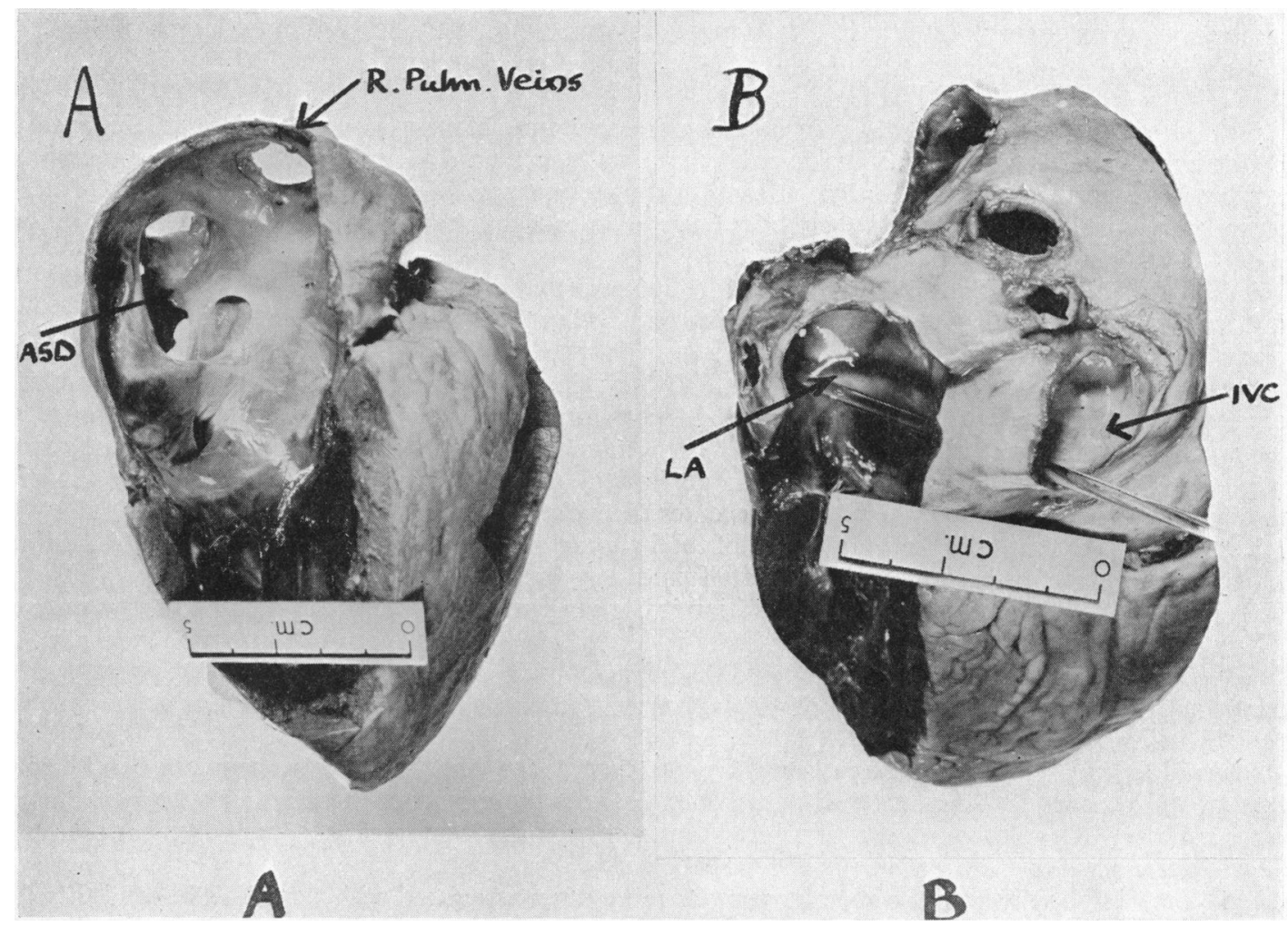

FIG. 4.-(A) Anterior view of the heart of patient with atrial septal defect and anomalous pulmonary and caval venous drainage. The pulmonary veins from the right lung enter the roof of the right atrium (arrowed). The fenestrated septal defect (A.S.D.) is well shown. (B) Posterior view. A glass rod passes through the inferior vena cava (I.V.C.) which enters the left atrium (L.A.).

tion is very dfficult to diagnose, and I should like to ask the surgeons present how much embarrassment anomalous venous drainage is likely to cause during an operation for closure of an A.S.D. A high A.S.D. involving tissue postero-superior to the fossa ovalis tends to be associated with anomalous pulmonary veins, and the superior vena cava may override the septum causing slight right-to-left shunting. Dye dilution techniques have shown preferential shunting from right to left of superior caval as opposed to inferior caval blood (Swan et al., 1957).

I should now like to consider the diagnosis of partial anomalous venous drainage without A.S.D. I have never diagnosed such a case. I should like to know whether the physical signs and the electrocardiogram are the same as in A.S.D. Obviously, the differential diagnosis from A.S.D. is of the greatest importance. The detection of any right-to-left shunt by dye dilution techniques would presumably indicate the presence of an inter-atrial communication (Swan et al., 1953). Alternatively, if differential dye studies from each lung showed a left-to-right shunt from one lung only, this might give the answer. Selective pulmonary arteriography in two planes might also afford the solution.

Finally, I wish to consider the prognosis of total anomalous venous drainage with special reference to size of the inter-atrial defect, and the presence of obstructive pulmonary hypertension. Presumably, survival depends upon the size of the A.S.D., and early death may be associated with 
a very small defect. Obstructive hypertension would tend to increase the right-to-left shunt at atrial level. This might impair the function of a hypoplastic left ventricle and produce left ventricular failure, although this might well be prevented by restriction of inflow from the pulmonary veins. Two patients in my series are only moderately incapacitated although having considerable pulmonary hypertension. I should like to provoke discussion on whether some degree of elevation of pulmonary resistance may not actually help these patients.

W. Somerville. An angiocardiogram may demonstrate anomalous pulmonary veins draining into the right atrium. The medium should be injected via a catheter placed in the right ventricle or pulmonary artery and late opacification of the right atrium from pulmonary veins may be seen in the postero-anterior and/or lateral planes. However, an associated large left-to-right shunt through an A.S.D. may obscure the details of right atrial opacification.

J. Shillingford. Swan uses dye curves to differentiate between pulmonary veins draining into right and left atria by injecting dye into the anomalous veins and noting the appearance time at the periphery and the shape of the curve.

$W . P$. Cleland. The anatomy is important. If the veins enter near the septum they can be excluded from the right atrium when the septum is repaired, but unfortunately, this only applies to a small group. In cases where the veins enter further away from the septum more time is needed for restoration of the normal anatomy and an extra-corporeal circulation is necessary. Tomography may help to determine the exact anatomy, particularly in cases where the veins enter the right atrial border.

J. D. Hay. We have seen four fatal cases of total anomalous pulmonary venous drainage in 128 infants with congenital heart disease. Maude Abbott found only four in 1000 autopsies on patients of all ages. This suggests a high death rate from this condition in the early years of life and the need for early treatment.

Arnold Johnson (of Montreal). In four cases with total anomalous venous drainage of the lungs, the veins drained below the diaphragm and entered the left portal vein and ductus venosus. One was diagnosed during life by angiocardiography. Histological changes in the lungs of these cases were similar to those seen in mitral stenosis.

D. J. Waterston. Most of these cases must come to operation and the exact anatomy can best be determined at thoracotomy. When the veins enter high up near the mouth of the superior vena cava there is always a danger of narrowing the caval orifice if an attempt is made to repair the anomaly: it is preferable to ligate these veins and do a right upper lobe lobectomy.

$P$. Wood. High veins into the superior vena cava are often associated with a small defect and therefore the shunt from the veins may be the more important factor. I agree with Somerville about the difficulty of clinical diagnosis in cases of total anomalous pulmonary veins from one lung and no A.S.D. Is the degree of plethora in the two lungs the same in this condition?

J. F. Goodwin (in reply). I find no difference in the two lungs radiologically. Selective angiocardiography into the pulmonary artery may be disappointing in this condition owing to the dilution of dye by the large blood flow.

\section{THIRD SESSION CHAIRMAN: WILLIAM EVANS}

\section{Pulmonary Hypertension with Reversed Shunt (EISENMENGer's Syndrome)}

\section{(1) The Nature of the High Pulmonary Vascular Resistance}

OPENED BY W. WhitakeR

In the time at my disposal I cannot discuss fully the controversial issue of the relative parts played by vascular spasm and structural disease in the pathogenesis of the high pulmonary vascular resistance. I shall confine myself to a description of the histological abnormalities occurring in the small pulmonary blood vessels of patients with severe pulmonary hypertension.

Heath and I have studied many patients with congenital and acquired heart disease and have found a close association between the histological appearances in the small pulmonary blood 
vessels and pulmonary arterial pressure. Where the pressures were normal or only slightly raised, the mean being below $50 \mathrm{~mm}$. $\mathrm{Hg}$, the pulmonary blood vessels were normal; but with higher pressures there were structural changes, and with mean pressures of 50 to $70 \mathrm{~mm}$. a media was found in vessels less than $100 \mu$ in diameter, which we accepted as pulmonary arterioles. Someone is bound to assert that these small vessels were not arterioles but contracted muscular arteries and it is impossible to deny that vascular spasm could account for the appearance of a media in vessels less than $100 \mu$. However, in patients with more severe degrees of pulmonary hypertension, where the pressures were of the order of the systemic pressures, there was in addition to medial hypertrophy extensive structural changes in the intima. In this group of patients we invariably found medial hypertrophy and proliferation of the intimal tissue in the muscular pulmonary arteries and in the pulmonary arterioles: in many vessels the lumen was obliterated by the proliferated intimal tissue, and I believe that these organic changes are responsible for the high pulmonary vascular resistance in Eisenmenger's syndrome.

Occasionally, but not consistently, other abnormalities were found in the small pulmonary blood vessels of patients with severe pulmonary hypertension. In some there was aplasia of the media, and in others there were dilated branches arising from the muscular pulmonary arteries proximal to their site of obliteration, in others obliterated vessels were recanalized, and occasionally in patients with severe idiopathic pulmonary hypertension arteriolar necrosis was seen.

In conclusion, I would like to make a plea about terminology. It is unfortunate that the term Eisenmenger's syndrome has been coined to describe all cyanosed patients with severe pulmonary hypertension. While I am quite happy to see the diagnosis Eisenmenger's complex preserved in cyanosed patients with ventricular septal defect and pulmonary hypertension, I am offended by such terms as "An Atrial Septal Defect Eisenmenger's Syndrome". Since it is now recognized that cyanosed patients with severe pulmonary hypertension not only present as a clinical entity but also have characteristic pathological features, I would suggest as an appropriate diagnosis in such cases Hypertensive Pulmonary Vascular Disease.

P. Wood. The pulmonary hypertension of Eisenmenger's syndrome is merely a failure of the pulmonary vascular resistance to diminish after birth. These slides illustrate that there is no release of the pulmonary vascular resistance by acetyl choline in the Eisenmenger syndrome as compared with primary pulmonary hypertension. There is thus no functional vasoconstriction in the adult, but the situation may be different in childhood.

M. Campbell. Wood's first remark may be true in P.D.A. with a reversed shunt; it is rarely true in A.S.D., and in V.S.D. many cases have hyperkinetic pulmonary hypertension at first and develop increased pulmonary arteriolar resistance some years later.

$J$. F. Goodwin. In the adult patient with Eisenmenger's syndrome, hexamethonium fails to produce any change in pulmonary vascular resistance as compared with pulmonary hypertensive mitral stenosis.

Arnold Johnson (of Montreal). The earliest age at which I have seen intimal thickening in the Eisenmenger syndrome in childhood is six years: this suggests that there may be some functional vasoconstriction as well in childhood.

R. E. Bonham-Carter. In cases of patent ductus with pulmonary hypertension, biopsy of the lung, using sections taken a uniform distance from the hilum, has shown regression of arterial change after operation.

William Evans. The vessels that Whittaker has shown on his slides are in fact small arteries that have undergone post-mortem contraction, as shown by the waviness of the internal elastic lamella, rather than arterioles that had developed muscle in their walls. $R$. H. Hudson agreed with Evans.

\section{(2) Identification of the Site of the Shunt in Cases of Reversed Shunts IN A.S.D., V.S.D., AND P.D.A.}

Opened by Wallace Brigden

Recognition of the site of the shunt in Eisenmenger's syndrome is often difficult, even after full clinical and laboratory investigation. Necropsy sometimes proves that it was incorrectly diagnosed 
even after elaborate tests. Symptoms such as dyspnœa, effort pain, effort syncope, and hæmoptysis are essentially due to pulmonary hypertension and are not related to the site of the shunt. Symptoms and signs may develop at any age, but their appearance in older patients is more common with late reversal of the shunt in A.S.D. Cyanosis may be present from birth or develop at any time later in all three, but late reversal is most common in A.S.D. Women preponderate among patients with reversed shunts in A.S.D. but the sexes are about equally affected in V.S.D. and P.D.A.

Physical signs are dominated by those of pulmonary hypertension and reversal of the shunt. Differential cyanosis clearly points to a P.D.A. An early diastolic murmur that can be firmly attributed to aortic rather than pulmonary regurgitation points strongly to V.S.D. with involvement of an aortic valve cusp. Atrial fibrillation is more common with reversed shunts in A.S.D.

$\mathrm{X}$-rays may be helpful but here also the main abnormalities are due to pulmonary hypertension. Evidence of anomalous pulmonary veins points to an A.S.D. A patent ductus may be suggested by local calcification in its wall or in the contiguous pulmonary artery, or by a bulge into the adjacent left bronchus. Differential size of heart chambers is helpful if left atrial or left ventricular enlargement is recognizable but it is usually not so in patients with great pulmonary hypertension. The electrocardiogram of each of these conditions tends to be similar when pulmonary hypertension induces shunt reversal, but sometimes a large $\mathrm{R}$ and deep $\mathrm{S}$ in mid-chest leads point to a V.S.D.

Passage of a cardiac catheter provides good evidence of the shunt site but a second shunt may be missed, a foramen ovale may cause error, and oxygenated blood from pulmonary regurgitation may suggest a V.S.D. when none exists. Catheterization of anomalous pulmonary veins indicates an A.S.D. Dye dilution curves should indicate early or late passage across to the left side; systemic vasodilators should cause a fall in pulmonary arterial pressure in reversed V.S.D. or P.D.A.; and a Valsalva manœuvre causes intensification of the shunt at A.S.D. level. All of these elaborate tests require further investigation to assess their accuracy in differential diagnosis.

W. Somerville. Retrograde arterial catheterization and angiocardiography would pick out the cases with a patent ductus. The condition might be reversible in the first year of life and an attempt should be made to establish the diagnosis at that age.

C. G. Parsons. Dr. Astley obtains satisfactory retrograde aortograms in children up to the age of 10 years by injecting into the brachial artery through a canula. This will demonstrate an open duct when there is left-to-right shunt or when pressures are balanced. Reversed flow is more readily diagnosed by venous angiocardiography.

R. M. Marquis. We have obtained good angiocardiograms using only a canula in the radial artery. When there is shunt reversal from birth, the aorta is characteristically small in persistent ductus, so a small aorta cannot be used as reliable evidence of an A.S.D.

L. McDonald. T1824 injections could be most helpful if the curves were acceptable.

M.B. Mcllroy. The pattern of change recorded with an ear oximeter in response to Valsalva's manœuvre changed with the level of shunt.

R. E. Bonham-Carter. At Great Ormond Street we tend to establish the diagnosis by exploratory thoracotomy.

Brigden, Whittaker, and Campbell were critical about the term Eisenmenger's syndrome, but Gibson, Somerville, and Wood said it was convenient, because this was how the patient presented at the bedside.

\section{(3) The Level of Pulmonary Vascular Resistance that Contraindicates Operation}

Opened by W. P. Cleland

My own experience with the condition under discussion is limited, but it is of the greatest concern to us all now that surgery of ventricular septal defects (V.S.D.) is being undertaken in this country. The group of V.S.D. with hypertension is most important but we can use our experience of patients with P.D.A. and A.S.D. and hypertension to guide us in our approach. I shall not speak about the pathology of the pulmonary vessels nor about the mechanism of production of the hypertension, both of which have been discussed already. 
I would like, first, to consider patent ductus arteriosus (P.D.A.) and to show a chart of a girl, aged 16, on whom I recently closed a ductus. The pulmonary artery pressure was $159 / 100$, the aortic pressure 130/90; the systemic blood flow was calculated as $41 . / \mathrm{min}$., and the pulmonary flow as $6.3 \mathrm{l}$./min., making the pulmonary vascular resistance 17 units. I show this slide (Fig. 5) of the

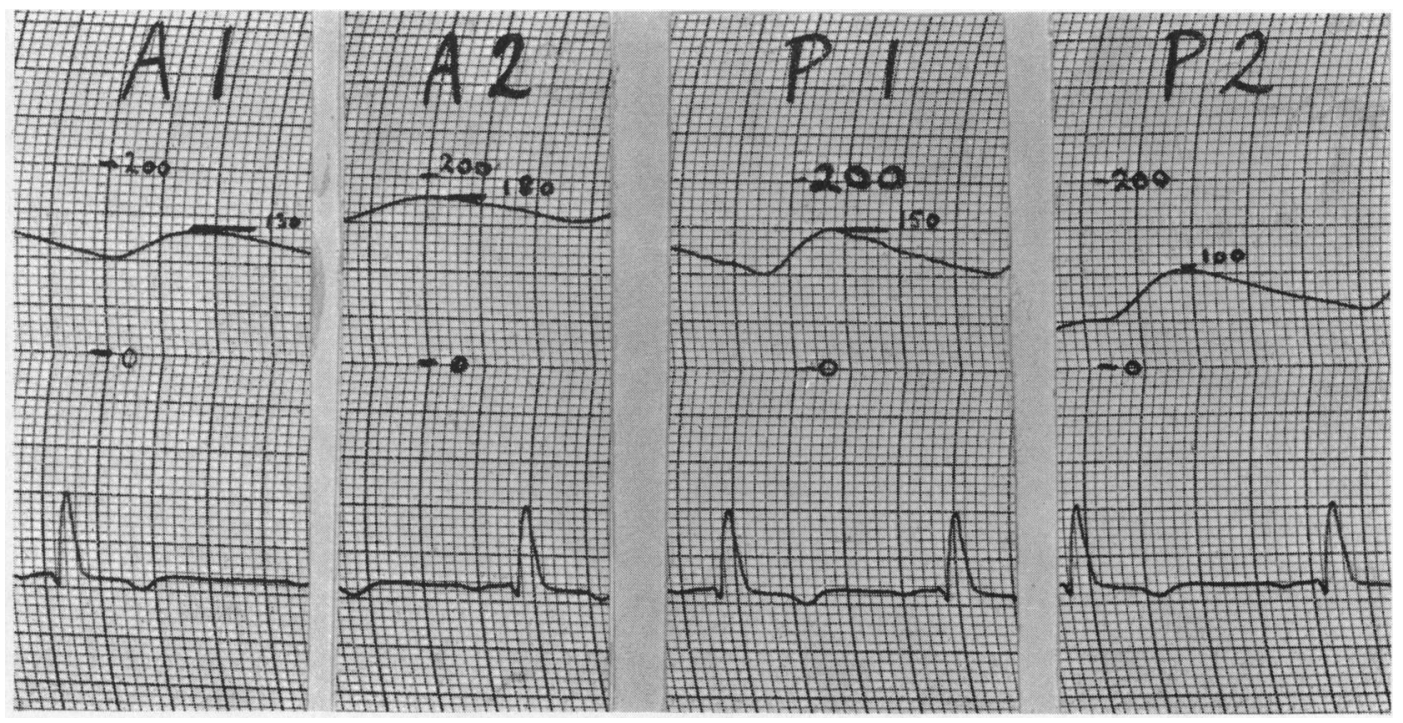

FIG. 5.-Tracings of pressure in the aorta and pulmonary artery before and after ligation of the ductus, (A) in the aorta and (P) in the pulmonary artery. (1) Before operation, and (2) after operation.

aortic and pulmonary arterial pressures before and after occlusion of the duct, not because it is unusual, but because it is what we expect in this group of cases.

Altogether I have treated 14 patients, 4 adults and 10 young children, with hypertension and a ductus, all still shunting from left to right. One had an associated A.S.D. and another a V.S.D. The post-operative course was uneventful in all but two: one who had a stormy period with cardiac failure was the child with the V.S.D. My experience suggests that even with balanced pressures there is usually an immediate fall in the pulmonary arterial pressure and a simultaneous rise in the aortic pressure, and that the prospects of a satisfactory outcome of a surgical closure are extremely good. Silver et al. (1954) from the Mayo Clinic have demonstrated a marked reduction in pulmonary pressures and a fall in pulmonary vascular resistance by late post-operative catheterization.

The situation is different with atrial septal defects. There are more middle-aged patients presenting with hypertension, and this complication appears to be more dangerous from the surgical point of view. The pathological changes in the pulmonary arteries and arterioles are degenerative in type with narrowing of the lumen from intimal fibrosis and proliferation. Campbell et al. (1957), Bedford et al. (1957), and Edwards et al. (1955) have all described these changes occurring in their series and almost every reported surgical series describes one or two patients dying from this complication. The sudden reduction in pulmonary blood flow following closure of the defect seems to precipitate a thrombotic obstruction which may result in death. I have had one patient developing a pulmonary infarct on the second day after operation, presumably from complications of this sort, although fortunately the patient survived.

Turning to the ventricular septal defects I am obliged to rely mainly on reported cases-the extensive series from Minneapolis (Warden et al., 1957) and from the Mayo Clinic (DuShane et al., 1956). The former group point out that most of their patients had pulmonary hypertension and 
that the average pulmonary pressure was 70 per cent of the systemic and think that the risks of operation are increased in the presence of hypertension. The Mayo Clinic have presented a very welldocumented account of the first 20 they have closed with the aid of the Gibbon machine. Eleven of their patients had a pulmonary arterial pressure of 80 per cent or more of the systemic pressure. In nine the pulmonary vascular resistance lay between 7.5 and 17 units, while in seven it was between 3 and 7 units. All patients, however, had a left-to-right shunt, the average shunt being 54 per cent, though in six there was a small right-to-left shunt also. Pressure recordings taken immediately before and after closure indicated an immediate fall in pulmonary pressure and their behaviour, in very many ways, was similar to that of the patients with a ductus and hypertension. There were 4 deaths in their first 20 cases, all due to pulmonary complications (atelectasis, bronchitis, etc.).

This work suggests that the V.S.D. is in many respects similar to the P.D.A. but behaves differently from the A.S.D. My present view is that I will be prepared to attempt the closure of a V.S.D., even when pressures are balanced and the resistance is high, provided there is still a reasonable leftto-right shunt, but this view is based on the experience of others and not my own.

M. Campbell. I am surprised that a girl with a pulmonary vascular resistance of 17 units has done well, for generally a level much lower than this contraindicates operation. In patients with ventricular septal defect the resistance tends to rise with age and so perhaps we should aim at operating on younger patients.

$P$. Wood. There must, I think, be a mistake in the calculation of the resistance or the patient may have been hypertensive with a raised systemic resistance.

A. Leatham. Findings at catheterization do not always reflect the patient's normal state, and the electrocardiogram may be a more reliable guide than a single reading of pulmonary pressure.

R. M. Marquis. Unfortunately persistence of a left-to-right shunt at catheterization does not necessarily imply that operation will be successful. Of six patients with a raised pulmonary vascular resistance and small left-to-right shunts through a persistent ductus but without shunt reversal, three died suddenly after operation, two within 24 hours and the third five months later with increasing dyspnoea and angina. The three remaining patients aged 8,10 , and 23 , were recatheterized one to four years after operation and the pulmonary vascular resistance remained raised, though the pulmonary systolic pressures were lower but still in the region of $60-70 \mathrm{~mm}$. Hg.

W. Somerville. A patient who had an A.S.D. and a pulmonary vascular resistance of 8 units died at operation. I do not as a rule recommend operation for A.S.D. if the resistance exceeds 5 units.

R. Gibson. One patient with A.S.D. and a raised resistance had thrombosed the whole of her pulmonary vascular bed during the period of circulatory arrest at operation.

J. D. Hay. A shunt that is usually from left-to-right may become balanced or reversed during operation owing to the fall in systemic pressure during anæsthesia. The only death in the first 100 children operated upon by Mr. Edwards was in such a child: because the shunt at operation was from right-to-left he did not close the ductus and the child died shortly after the operation: had he closed it, she might have lived.

W. P. Cleland (in reply). Surgery cannot, I think, help patients with right-to-left shunts. There is a serious risk of thrombosis during circulatory arrest for operation on an A.S.D. with raised pulmonary vascular resistance.

\section{Differential Diagnosis of Fallot's Tetralogy and Simple Pulmonary Stenosis WITH A REVERSED INTER-ATrial SHUNT}

Opened by Maurice Campbell.

I propose to give you 18 points that help to distinguish Fallot's tetralogy from simple pulmonary stenosis. The first five are more likely to be found in Fallot's tetralogy, where the physique is generally poor and the chest often deformed (1); where squatting occurs in 85 instead of 15 percent (2); where the clubbing of the fingers is more severe (3); where the cyanosis occurs earlier, 
nearly always before eighteen months (4); and where it is generally more severe, the hæmoglobin ranging between 120 and 149 with an average of 134 per cent (5), while in simple stenosis it ranges between 100 and 139 and averages 120 per cent. In contrast there may be a greater increase of cyanosis on exertion in simple pulmonary stenosis.

The next four points are physical signs. These are less striking in Fallot's tetralogy, where their value is negative rather than positive. On the other hand, in simple pulmonary stenosis of any severity, and cyanotic cases must be severe, there is a prominent $a$ wave in the jugular pulse (6), the systolic murmur is louder and longer (7), the degree of splitting of the second sound is increased during expiration by delay in pulmonary valve closure (8), and the aortic component is not increased (9) as it may be in Fallot's tetralogy.

The next five points deal with radiology and the electrocardiogram. In Fallot's tetralogy the heart is of normal size unless there are complications (10), there is a deep pulmonary bay (11), and strikingly oligæmic lung fields (12). In cyanotic pulmonary stenosis the heart is nearly always enlarged and may be greatly so (10), the pulmonary artery is more dilated beyond the stenosis and tends to fill in the pulmonary bay (11), and the lung fields are less oligæmic (12) for until a late stage the pulmonary flow is kept at a normal level by the hard work of the right ventricle. The aortic arch is right-sided in 25 per cent of cases of Fallot's tetralogy and rarely in pulmonary stenosis (13). In both the cardiogram shows right ventricular preponderance but severe right ventricular strain with $\mathrm{T}$ inversion to $\mathrm{V} 4$ favours simple pulmonary stenosis (14).

Catheterization may be decisive for in Fallot's tetralogy the right ventricular pressure is about the same as the systemic, while in simple pulmonary stenosis it differs from the systemic in threequarters (15), ranging between 40 and $200 \mathrm{~mm}$. Evidence that the stenosis is infundibular makes Fallot's tetralogy more likely (16) but does not, of course, exclude a closed ventricular septum.

Angiocardiography should show the shunt from the right to the left atrium (17), and there is less likely to be simultaneous filling of the pulmonary trunk and aorta (18).

With all these differences it may seem that there should never be much difficulty, but most of them are usual rather than universal and there is overlapping. Difficulty is most likely to arise in patients with Fallot's tetralogy who are relatively fit with little cyanosis or sometimes in those with extreme ventricular strain. When there is difficulty, angiocardiography should give the most decisive answer, but the differential diagnosis has been expressed in this way because the general picture, taking all these differences into account, is more likely to give the right answer than any one alone. Whether studies with dye curves will give a more decisive answer is still uncertain.

J. D. Hay. In infancy some of the differentiating points mentioned by Campbell will let one down: for example, in pulmonary stenosis with an A.S.D. cyanosis may be extreme and the pulmonary arc on X-ray may be concave because there has not been time for post-stenotic dilatation of the pulmonary artery to develop. Angiocardiography is the most reliable method of differentiating these lesions in infancy: occasionally the hypertrophy of the right ventricular wall so encroaches upon its cavity that it is not visualized by dye, which, with the filling of the left atrium from the right suggests tricupid atresia: right ventricular dominance in the cardiogram should prevent this misinterpretation.

R. E. Bonham-Carter. An infant with Fallot's tetralogy who becomes anæmic or relatively anæmic can have a very large heart (reversible on correction of the anæmia) and this can make one think first of pulmonary stenosis with reversed inter-atrial shunt.

J. Shillingford. Studies with T1824 have proved of value at the Mayo Clinic.

M. B. Mcllroy. We have been deceived by dye curves in this situation: maximum information should be sought in every way.

$R$. Gibson. In two cases, both with large $a$ waves, the right ventricular systolic pressure was 50 and $100 \mathrm{~mm}$. Hg greater than the systemic, but both had Fallot's tetralogy at operation.

$P$. Wood. One can be deceived by artefacts on right ventricular tracings which should always be scrutinized carefully.

M. Campbell (in reply). All the evidence must be weighed in each case. The differentiation cannot be made on a single test, though perhaps angiocardiography is the most decisive. 


\section{The Selection of Cases of Simple Pulmonary Stenosis for Surgical Treatment}

OPENED BY DAVID WATERSTON

Many surgeons have become dissatisfied with the "blind" right ventricular approach to the outflow tract, and now prefer to deal with the stenosis under direct vision through the pulmonary artery or the right ventricle. The slightly greater risk with this procedure makes the indications for surgery difficult at the present time.

There is no doubt that surgery should be advised in any case showing one or more of the following features.

(1) Cyanosis, whether this be due to a right-to-left shunt through an unsealed foramen ovale or not.

(2) Clinical signs of right ventricular strain, such as diminution in exercise tolerance, angina, or enlargement of the heart. Electrocardiographic evidence of right ventricular strain should not be relied on in young children.

(3) A right ventricular pressure approaching the systemic level. In the future it seems likely that all cases with a significant rise in right ventricular pressure should be subjected to operation; this should not be advised until the operative mortality approaches that for patent ductus, i.e. 1-2 per cent.

The operation of choice should allow for a direct vision approach with plenty of time to deal with the infundibular stenosis if necessary. Until this procedure becomes a safe one, the indications for operation must remain limited.

R. E. Bonham-Carter. Some children with pulmonary stenosis are cyanosed at rest, and standing makes them go nearly black. In two cases where I thought there was a right-to-left shunt, the septa were intact at necropsy. I therefore regard cyanosis-presumably peripheral-as an indication for operation. Cerebral disturbance is another indication: in two of three children, who had fits and abnormal electro-encephalograms, these returned to normal and the fits stopped after valvotomy.

$J$. D. Hay. It may be too late to wait for symptoms before advising operation: in 17 of 30 children symptoms were absent. We catheterize all our suspected cases in children and advise operation when the R.V. pressure is over $70 \mathrm{~mm}$. In five with a pressure above this the cardiogram was normal.

$W$. P. Cleland. Anyone operating on pulmonary valve stenosis must have been dismayed by finding subvalvular obstruction at a later date, even though the valve had been well split. The present tendency is to open up the infundibulum and remove some of the muscle there though we have no clear idea as to how much should be taken away. Is there any need to do this?

$P$. Wood. I believe there is; if this functional stenosis is left, patients do badly, for the stenosis and the muscular hypertrophy do not subside. Surgical removal of infundibular muscle does not give a good result and valvular stenosis is best operated upon before this functional stenosis appears. At present $I$ recommend operation in patients with R.V. systolic pressures of $75-80 \mathrm{~mm}$. Hg. Now that valvotomy under direct vision is giving better results perhaps milder cases with pressures of $50-60 \mathrm{~mm}$. should be sent for surgery.

H. E. Griswold (of Oregon, U.S.A.). The transventricular approach should not be abandoned too readily. With it, and using a special knife, my surgical colleagues are usually successful in reducing the valvular gradient to 10 or $20 \mathrm{~mm}$. Hg.

$W . P$. Cleland. Is the development of functional infundibular stenosis a question of time or is it related to the degree of valvular obstruction?

$P$. Wood. It never occurs with mild stenosis. It can occur with moderate stenosis and this may be devastating. I do not know when it begins but in severe stenosis it can be fully developed when the child is 8 years old.

C. G. Parsons. Cine-angiocardiograms taken by Dr. Astley in a child with valvular stenosis showed a wide infundibular canal during ventricular systole. When the heart was examined at necropsy a false impression of infundibular stenosis was produced by the tremendous muscular hypertrophy of the infundibular canal. 
High R.V. pressure may make it impossible to demonstrate a septal defect by catheter. After successful operation for pulmonary stenosis and closure of an A.S.D., a child developed a large left-to-right shunt (double the systemic blood flow) through a previously unrecognized V.S.D.

D. J. Waterston (in reply). In our present state of knowledge the surgeon must always be prepared to open up the outflow tract when operating on pulmonary valve stenosis.

FOURTH SESSION

\section{The Surgical Treatment of Pulmonary Stenosis complicated by A.S.D. With Direct OR REVERSED SHUNT}

\section{OPENED BY J. D. HAY}

Our experience in Liverpool is mainly confined to infants and children, and to a short followup, but this has raised some of the main questions. A decision about the advisability and type of surgical treatment for this combination of lesions has to be faced not infrequently now that both operations are reasonably safe. The presence of both lesions must, of course, be demonstrated, and the direction of the interatrial shunt established.

We have already discussed the significance of the pressure gradients across the pulmonary valve in the presence of a left-to-right shunt through an A.S.D. and it seems that we have to be very cautious in their interpretation. The site of stenosis must also be defined. Catheterization and selective angiocardiography is the best method of settling the site in all but infants and perhaps toddlers; in them a venous angiocardiogram is usually adequate and will, of course, reveal also a right-to-left shunt through an A.S.D. and help to differentiate the condition from Fallot's tetralogy.

With regard to the diagnosis of the A.S.D., firstly is an $\mathrm{rsR}^{\prime}$ pattern usually present when the shunt is from left to right and usually replaced by the pattern of R.V. strain when the stenosis is dominant and the shunt balanced or reversed? Or, to put it another way, when the stenosis is dominant is the absence of a rsR' pattern against the presence of an A.S.D.? Not always, I think.

Secondly, when catheterization in a case of pulmonary stenosis shows no left-to-right shunt or one apparently at ventricular level, what other measures are of most value to demonstrate or exclude an A.S.D.? Should we always catheterize a case of pulmonary stenosis via the saphenous vein because an A.S.D. may be traversed much more easily by this route, even though it is more difficult to enter the pulmonary artery? Should we use a balloon catheter to estimate the size of the defect? I think it may be of value when the shunt is balanced or reversed, but may give a fallacious impression that the defect is small when in fact it is large, because it tends to catch on the wall of the defect on withdrawal. Or should we rather resort to angiocardiography, which will nearly always reveal the A.S.D. when there is a balanced or reversed shunt, but may not give much idea of its size?

As regards the indications of surgery, may I put forward our present view in Liverpool to stimulate discussion? If there is valvular stenosis and the right ventricular systolic pressure is over $45 \mathrm{~mm}$. $\mathrm{Hg}$ and X-ray shows an absence of much pulmonary plethora, our aim is to avoid the continued strain of the combined lesions upon the right ventricle. Therefore, whether cardiac catheterization reveals a small left-to-right shunt through the defect or not, we would advise, and have in two cases advised, an immediate valvotomy, to be followed at once by closure of the defect if the condition of the patient permits. If no A.S.D. is found but only a small patent foramen ovale which might close spontaneously later, it might reasonably be left alone.

If a valvular stenosis is accompanied by a right-to-left shunt through the defect, as indicated by cyanosis, and if this is increasing or accompanied by dyspnœa, valvotomy is clearly the first step to 
be undertaken when a complete correction is considered practicable. Following the valvotomy, a large A.S.D. should probably be closed at once, if possible, and a small one left alone in the hope that it may close spontaneously. In infants, valvotomy may be life-saving, as we have seen in one case. In some infants, an anastomosis may be more practicable and may be performed as a first aid measure with a view to valvotomy and closure of the A.S.D. later by open heart surgery.

If a left-to-right shunt through the A.S.D. is dominant, and there is much pulmonary plethora, the defect should be closed and the residual pressure gradient across the pulmonary valve, measured: if there is a significant valvular stenosis, valvotomy should follow, but we have had no such case.

P. Wood. The problem of what to do with an A.S.D. in patients with pulmonary stenosis arises because of the success of pulmonary valvotomy done under direct vision. The R.V. pressure may be reduced to a level where a large left-to-right shunt will appear. Is there any way of telling the size of the A.S.D. apart from estimates based on catheterization or angiocardiography?

M. B. Mcllroy. Using the Valsalva manœuvre we can demonstrate the presence of a defect at atrial level but not its size. However, a patent foramen ovale appears to be too small to detect by this means.

D.J. Waterston. The problem will be solved when, with hypothermia, the surgeon feels for a defect as a routine.

$P$. Wood. This is not my experience and surgeons are already missing such defects: a cardiologist should be able to tell the surgeon beforehand whether a defect is present or not.

M. Campbell. I disagree with one of Hay's criteria for operation: a ventricular pressure of $45 \mathrm{~mm}$. is just high enough to cut down an atrial shunt and the patient can safely wait until the surgeon is ready to deal with the pulmonary stenosis and the septal defect at one operation.

J. D. Hay (in reply). I should have made it clear that we are prepared to perform valvotomy and close the A.S.D. at the same operation if the condition of the patient permits. I agree with Wood that we physicians ought to make certain of the presence of an A.S.D. complicating pulmonary stenosis. Catheterization via the saphenous vein seems the most reliable method of achieving this with, perhaps, the employment of a balloon catheter, although I personally do not like using one because of the hazards mentioned.

\section{Attacks of Deeper Cyanosis and Loss of Consciousness (Syncope) in Fallot's TETRALOGY}

Opened by Paul WoOd

A history of syncope is obtained in about 20 per cent of all cases of Fallot's tetralogy, and is as common when the stenosis is valvular as when it is infundibular. Attacks are spontaneous and begin with increasing dyspnœa and cyanosis until consciousness is lost. Although the great majority recover, fatal syncope remains an important cause of death in Fallot's tetralogy, so much so that any patient giving this history receives high priority for surgical treatment.

It has been thought that the attacks are precipitated by a simple fall in blood pressure, such as occurs in vasomotor syncope in young persons; in Fallot's tetralogy a vasomotor turn of this sort immediately causes a sharp increase in the right-to-left shunt as the peripheral resistance decreases. This situation can be reproduced easily enough by giving a vasodilator substance such as amyl nitrite. Fig. 6 and 7 show the effect. There is an immediate fall in blood pressure accompanied by cyanosis and a drop in the arterial oxygen saturations; simultaneously the pulmonary artery pressure pulse declines both in the mean level of pressure and in the amplitude of the pulse.

Five cases of Fallot's tetralogy with a history of syncope have been studied. The findings have been uniform whether in an actual attack of syncope or in an episode of spontaneous dyspnœa and cyanosis short of syncope. Table I summarizes the findings and from them the following comment can be made.

(i) The blood pressure did not fall in any of the attacks. A peripheral vasoconstrictor (methedrine) was given in one case, and although the blood pressure rose from 100 to $150 \mathrm{~mm}$., the extremely low arterial oxygen saturation (below $10 \%$ ) remained unchanged. It is concluded with confidence that peripheral vasodilatation is not the cause of these attacks. 
(ii) A consistent finding was the shortening, softening, and eventual disappearance of the pulmonary systolic murmur according to the degree of fall in arterial oxygen saturation. When consciousness was lost no murmur could be heard at all, suggesting that there was then a state of functional pulmonary "atresia". The extremely low arterial oxygen saturation confirmed that this was the actual cause of the loss of consciousness, and it is obvious that during the attack there is a largely increased deviation of blood from the lung, i.e. a sharp increase of right-to-left shunt.

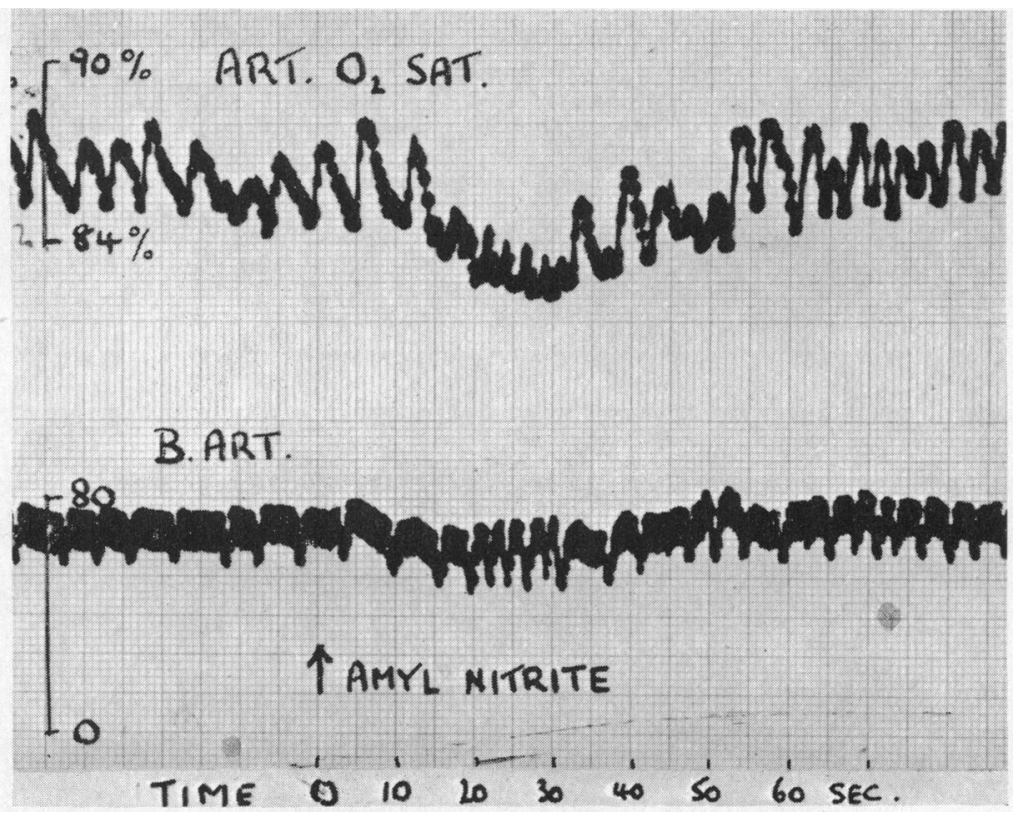

Fig. 6.-Effect of amyl nitrite on the brachial artery pressure and arterial oxygen saturation in Fallot's tetralogy.

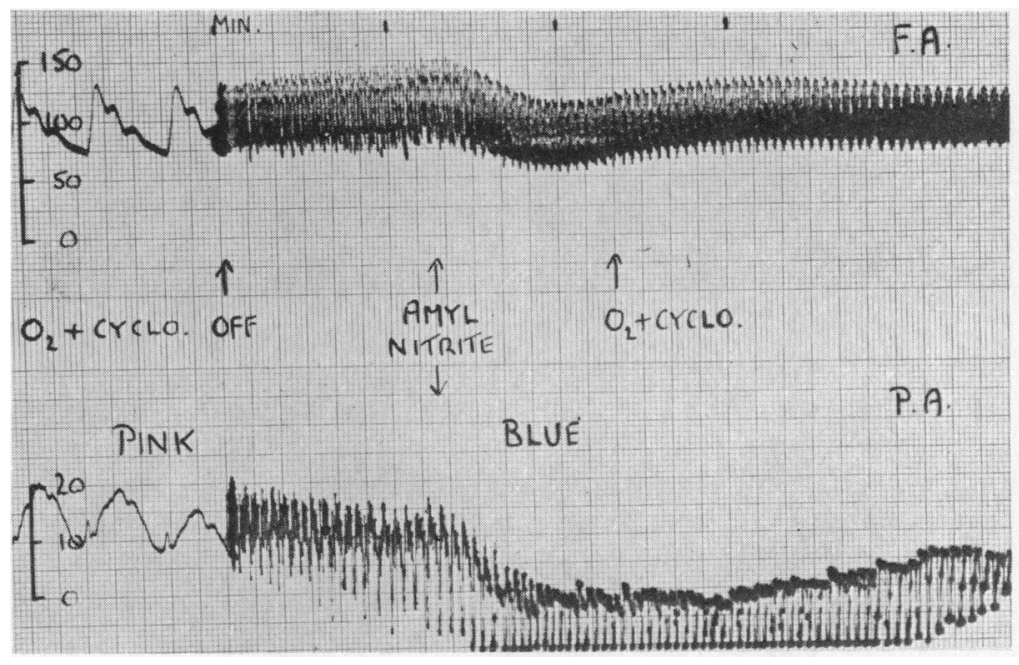

FIG. 7.-Effect of amyl nitrite on the pulmonary artery pressure and pulse (lower curve) and femoral artery pressure (upper curve) in Fallot's tetralogy. The sharp negative pressure swings in the P.A. tracing represent inspiration. 
TABLE I

Changes during Attacks of Cyanosis and During Syncope in Fallot's Tetralogy

\begin{tabular}{|c|c|c|c|c|c|c|c|}
\hline & & & & & Usual state & $\begin{array}{l}\text { In attack of } \\
\text { dyspnœa and } \\
\text { cyanosis }\end{array}$ & During syncope \\
\hline Cyanosis .. & . & .. & .. & .. & Slight & Moderate & Severe \\
\hline Arterial $\mathrm{O}_{2}$ satur & ration & .. & .. & .. & Around $80 \%$ & Around $50 \%$ & Around $20 \%$ \\
\hline Pulse rate .. & . & .. & . & .. & Approx. 90 & Approx. 120 & Approx. 150 \\
\hline Jugular venous $p$ & pulse & .. & . & . & Normal & Normal & Normal \\
\hline \multicolumn{3}{|c|}{ Pulmonary ejection murmur } & . & .. & Loud and fairly long & Soft and short & Absent \\
\hline Thrill & . & .. & .. & . & Present & Absent & Absent \\
\hline P.A. pressure & . & .. & .. & . & Fair & Low & Very low \\
\hline P.A. pulse. . & .. & .. & .. & .. & Good & Poor & Absent \\
\hline B.P. (systemic) & . & . & .. & .. & Normal & Unchanged & Unchanged \\
\hline
\end{tabular}

(iii) When discussing this problem with Howard Burchell in 1953, he suggested that the cause might well be breath-holding, a not uncommon phenomenon in infants and small children when emotionally disturbed. This might well cause pulmonary vasoconstriction secondary to a fall in alveolar oxygen tension. If this was the explanation, however, the pulmonary arterial pressure would rise. But on several occasions when increased cyanosis occurred during catheterization, the opposite was always found, as indicated in the Table. It follows that the deflection of blood from the lungs cannot be due to pulmonary vasoconstriction.

(iv) There is only one other anatomical site that might vary its resistance and so influence the quantity of blood sent to the lungs and the amount of the shunt, namely the infundibulum of the right ventricle. Since functional infundibular stenosis is common when the congenital stricture is at valve level, varying behaviour of the infundibulum would be expected to operate particularly in cases of Fallot's tetralogy with valve stenosis; or at any rate it would be expected to affect such cases at least as frequently as those with organic infundibular stenosis, and this has already been shown to be true. The thesis suggested is that during the attacks the infundibulum contracts more completely than usual and tends to block the outflow to the lungs. This would cause the murmur to shorten, and to disappear when the obstruction was complete. This, too, has been shown to occur.

In two cases observations made during catheterizations support this view. One patient, for example, was being anæsthetized with cyclopropane and was also having oxygen. It was noticed that the child was pink and that the pulmonary arterial pressure pulse was of high amplitude and running at a good mean pressure (Fig. 8). When both oxygen and cyclopropane were withheld the child became cyanosed. During this phase the murmur shortened and the pulmonary arterial pressure pulse declined sharply, both in mean pressure and amplitude. When oxygen was given the patient's colour improved somewhat, but he remained cyanosed, the murmur did not increase in length or intensity, and the arterial pressure pulse did not regain its proper contour or pressure level. When cyclopropane was added, however, there was a rapid change in the situation; the child turned bright pink, the murmur lengthened and became loud, and the pulmonary arterial pressure pulse regained its normal pressure and amplitude of pulsation. These events are summarized in Fig. 9. It is concluded that cyclopropane relieved infundibular over-action.

No information is available concerning the precise cause of the variability in infundibular behaviour, nor whether the effect of cyclopropane is specific or whether many other anæsthetics or strong sedatives would have the same effect. Taussig's original observation that the best treatment 


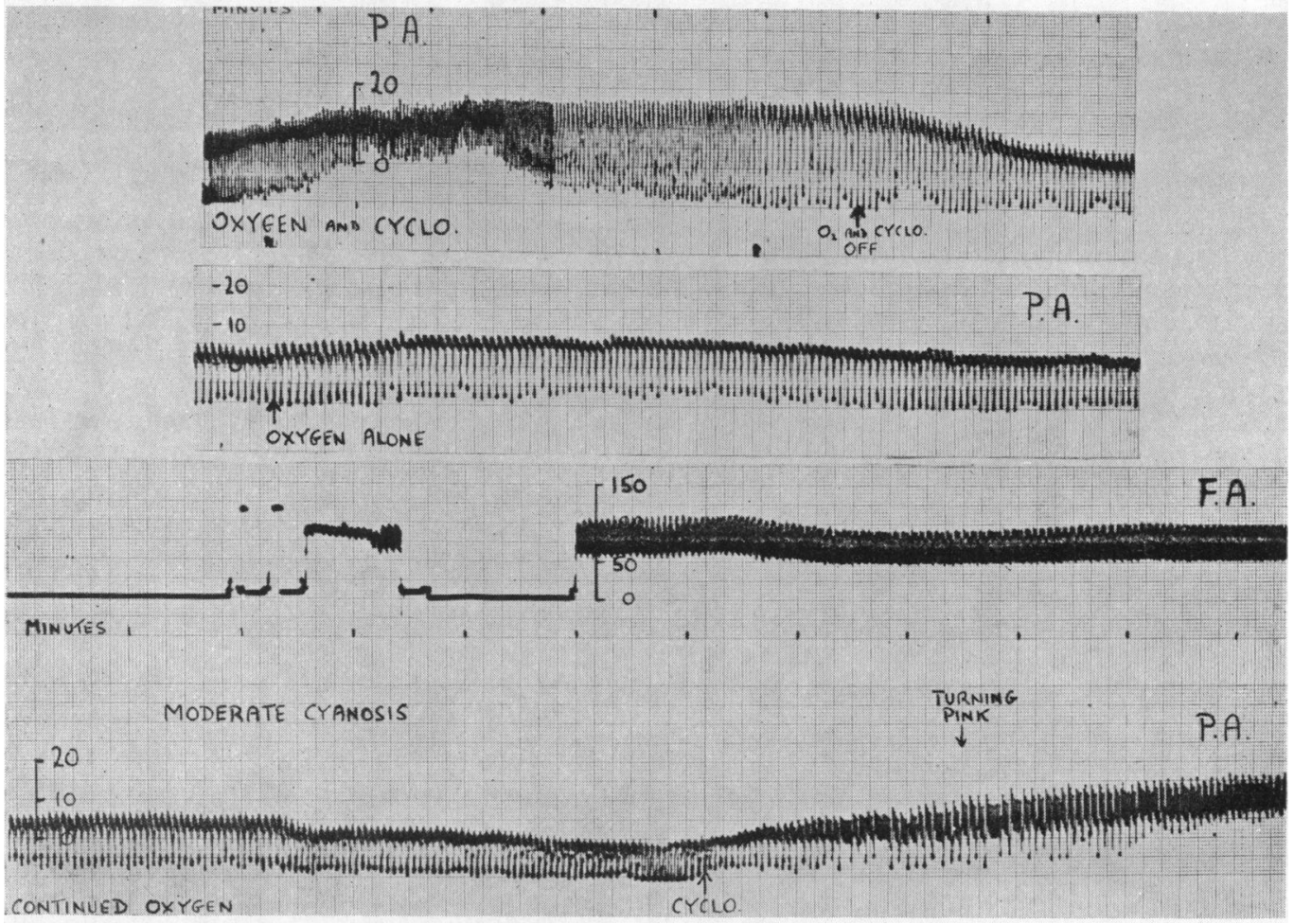

FIG. 8.-Continuous tracings, showing the effect of oxygen and cyclopropane on the pulmonary artery pressure pulse and skin colour in Fallot's tetralogy.
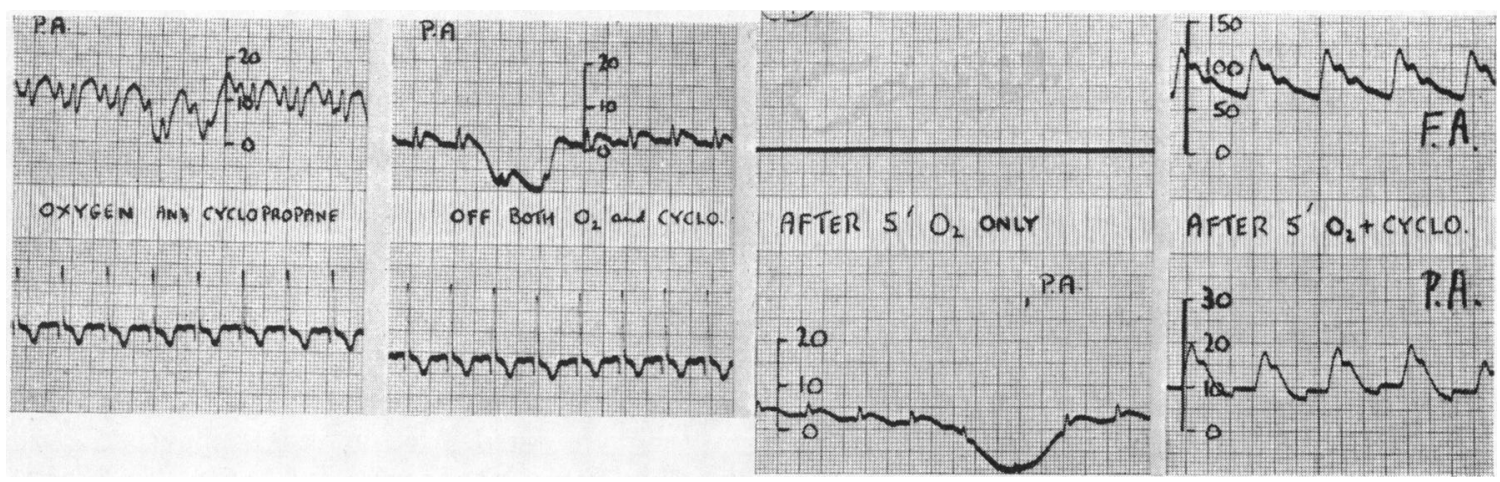

Fig. 9.-Selected tracings, showing the effect of oxygen and cyclopropane on the pulmonary artery pressure pulse in a case of Fallot's tetralogy. P.A., pulmonary artery; F.A. femoral artery.

of these attacks is morphine suggests that the action of cyclopropane may be non-specific. The thesis, however, is not so much that cyclopropane may relieve syncope in Fallot's tetralogy, but that the cause of the syncope is due to functional obstruction in the infundibulum and not to systemic vasodilatation nor to pulmonary vasoconstriction, although it is conceded that under special circumstances such mechanisms might be responsible.

$W$. Somerville. What initiates this functional infundibular stenosis and is it ever provoked by catheterization or angiocardiography? 
P. Wood. The attacks appear generally to be spontaneous though sometimes initiated psychologically. A point against the theory put forward is that one of my patients with pulmonary atresia had syncopal attacks.

B. G. B. Lucas. I have often noticed that when patients with Fallot's tetralogy are anæsthetized they became less cyanosed. Probably there is nothing specific in the action of cyclopropane and the treatment of syncope might be to render the patient quickly unconscious, for example with intravenous morphine.

J. D. Hay. In support of this observation is the fact that when children are anæsthetized, as for an angiocardiogram, they become less cyanosed. Wood's observations may partly explain why angiocardiography under general anæsthesia may suggest a wide infundibular canal in cases in which considerable infundibular stenosis is found at operation or autopsy.

$W$. Somerville. In hospital syncope is treated with oxygen and the patients recover (or, said Wood, they die).

B. G. B. Lucas. A patient with bronchospasm rarely dies for when he becomes unconscious and anoxic there is muscular relaxation.

$P$. Wood (in reply). There is probably nothing very specific about the action of cyclopropane. Aminophyllin has failed to relieve the attacks. The syncopal attack produces unconsciousness more quickly than does cyclopropane and it might therefore be argued that oxygen was contraindicated.

\section{The Differential Diagnosis of Shunts by Respiratory Techniques}

\section{OPENED BY M. B. MCIlRoy}

When a patient with a small or moderate shunt through an A.S.D. performs Valsalva's manœuvre, the arterial pressure falls off in the normal manner as the heart and lungs empty of blood. When the patient stops blowing, the venous return is restored and blood rushes into an empty right atrium: this produces a momentary increase in right atrial pressure which reverses the shunt and leads to a temporary fall in arterial oxygen saturation of 2-5 per cent, about three seconds after the pressure is released because of the heart-to-ear circulation time: this can be recorded using an ear oximeter. This sequence of events was described by Lee and Gimlette (1957). In patients with a large shunt at atrial level the response is different because the patient has a square wave Valsalva response and no shunt reversal occurs when the patient stops blowing. This test has been performed in 50 patients with an A.S.D. and those with pulmonary to systemic flow ratios of $4: 1$ and over tend to have square wave Valsalva responses while those under $4: 1$ tend to have a normal response and show shunt reversal either at rest or after exercise. These results confirm the work of Lee and Gimlette (1957) and show that this is a useful simple test for the detection of A.S.D. The test is not positive when there is a patent foramen ovale. It is useful in deciding if the defect has been completely closed at operation and should pick out cases with anomalous venous drainage of the right lung with an intact atrial septum.

The test is also useful in other forms of congenital heart disease, but uncomplicated shunts at ventricular or ductal level cannot be reversed. In patients with right-to-left or bidirectional shunts there are considerable changes in saturation during and after Valsalva's manœuvre which vary with the level of the shunt. Fig. 10A shows the pattern in reversed shunt at ventricular level in a patient with Fallot's tetralogy. The saturation first falls due to the inspiration before the blow, and then rises due to reduction in the right-to-left shunt; there is then a fall in saturation during the period of blowing which is the most distinctive feature of this response and is unexplained. The continued fall after Valsalva is due to resumption of the venous return.

The pattern found in reversed shunt at atrial level is different (Fig. 10B). Here the saturation rises throughout the period of blowing. The third pattern, found in patients with reversed shunt at aorto-pulmonary level, is shown in Fig. 10C. It resembles the pattern seen in interatrial shunt but the drop in saturation after Valsalva is delayed and prolonged, being maximal 7 seconds after the release of pressure. This is probably due to the increased pathway the blood has to travel through the right heart before reaching the shunt. The position is analogous to dye injection into the right atrium, except that the "dye" is venous blood. If the reversed shunt is at atrial level, 


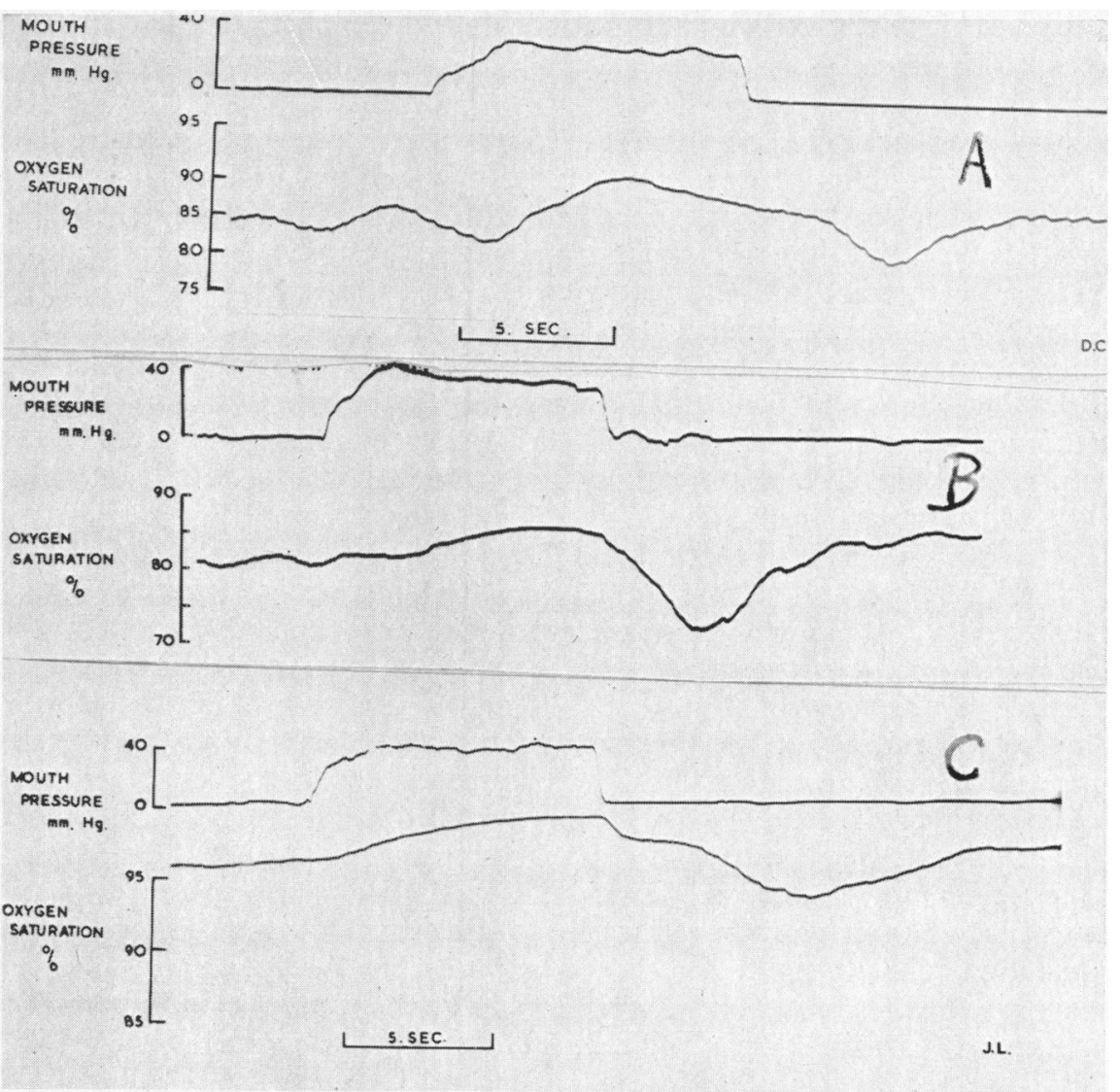

FIG. 10.-Arterial oxygen saturation during Valsalva's manœuvre in patients with a reversed shunt at (a) ventricular, $(b)$ atrial, and (c) aorto-pulmonary level.

the appearance time is short and the fall in saturation is abrupt. If the reversed shunt is at ductus level, the appearance time is longer and the fall in saturation is more spread out.

This short account of the use of Valsalva's manœuvre to produce different patterns of saturation change in different types of congenital heart disease has, I hope, been sufficient to show that this simple test can be of value in the diagnosis of congenital heart disease.

A. Leatham. How many normal subjects have been studied? The manœuvre might produce shunt reversal through a patent ovale.

M. B. McIlroy. Ten normal subjects have failed to show shunt reversal as did two patients with pulmonary stenosis who were known to have a patent foramen ovale. It is unlikely that normal subjects could show detectable shunt reversal through a foramen ovale.

$P$. Wood. It is important to establish this beyond argument before using the test post-operatively to confirm that an A.S.D. had been completely closed.

\section{Dye Dilution Curves in Congenital Heart Disease}

OPENED BY J. P. SHILlingFord

Stewart first showed the possibility of measuring the cardiac output by injecting an indicator substance into the venous circulation and sampling it in the arterial circulation. Hamilton and his 
associates confirmed these results in circulation models and demonstrated that an estimate of the volume through which the indicator had passed could be made by an analysis of the time concentration curve.

More recently Swan and his associates at the Mayo Clinic have made extensive use of the dye dilution technique for detecting the presence and position of intracardiac shunts. The technical problem of recording the concentration curves from either the ear or an arterial cuvette has in the past been considerable. With the development of suitable electronic amplifiers and recorders this has now been largely overcome and satisfactory curves can be recorded with little trouble. Evans blue (T1824) has been the indicator mainly used and its passage through the ear or a cuvette can be recorded by a photo-electric cell with a red filter; it has the disadvantage that its absorption spectrum falls within that of reduced hæmoglobin so that changes in oxygen saturation effect the curve. The introduction of a green dye (tricarbo-cyamine) may eliminate this trouble. Radioactive indicators have proved unsatisfactory for continuous sampling from a peripheral artery.

The dye dilution curve in the absence of a shunt is a "skew" distribution curve with an appearance time some seconds after the injection depending on the cardiac output and the volume that the dye passes. The upstroke is smooth in outline and the downstroke exponential in form. The introduction of a right-to-left shunt causes an earlier appearance time and a small hump on the upstroke of the curve, by some of the dye particles passing into the arterial circulation ahead of the main pari of the dye which passes through the lungs. The introduction of a left-to-right shunt does not alter the appearance time, but produces a series of small curves on the descending limb of the main curve due to small portions of the dye being sequestered by the shunt and passed on from subsequent pulmonary circulations. This also increases the overall spread of the curve.

Although these changes may be used as a simple screening test to show the presence of a rightto-left or left-to-right shunt they become far more valuable in diagnosing the lesions of congenital heart disease when used in association with selective injection through a cardiac catheter.

Exact localization of left-to-right shunts is made by injecting the dye through a catheter into the chamber concerned with the shunt and comparing the curve with a second injection made more distally and separated from the chamber by a competent valve. For example in V.S.D. left ventricular injection causes an abnormal and aortic injection a normal curve. In a similar way the localization of an A.S.D. may be made and the position of an aorto-pulmonary shunt in the region of the sinus of Valsava localized and separated from a P.D.A.

It is often difficult in cases of A.S.D. where the catheter has entered the pulmonary vein to know whether the vein enters the right or left atrium. The introduction of dye down the catheter and its recording as a dye dilution curve determines this by comparison with a curve drawn by injection into the superior vena cava in the same patient.

Differentiation between Fallot's tetralogy and pulmonary stenosis with reversed intra-atrial shunt can be made by injection into the right ventricle and right atrium. In the former case an abnormal curve is obtained only from the right ventricle and in the latter from the right atrium.

These examples illustrate some of the potentialities of the technique which is still in its infancy. It has, however, probably already reached the stage when it is ready to take its place alongside the cardiac catheter and angiocardiogram in the exact anatomical diagnosis of congenital heart lesions.

R. W. Emanuel. I have studied three patients where the diagnosis lay between Fallot's tetralogy and a reversed interatrial shunt. By injecting dye into the right ventricle the correct diagnosis was reached in each case. A further use is that if a patient has an A.S.D. an injection of dye into the inferior vena cava often passes across and produces an early appearance of the dye curve. This technique is of value when the catheter cannot be passed into the left atrium and where the rise in saturation at atrial level might be wrongly attributed to the presence of anomalous veins.

$P$. Wood. The technique is of value and facilities for dye injection should always be available during catheterization. It is particularly helpful in demonstrating the level of the shunt in patients with Eisenmenger's syndrome. 


\section{REFERENCES}

Barber, J, M., Magidson, O., and Wood, P. (1950). Brit. Heart J., 12, 277.

Bedford, D. E., Sellors, T. H., Somerville, W., Belcher, J. R., and Besterman, E. M. M. (1957). Lancet, $1,1255$.

Blount, S. G., Swan, H., Gensini, G., and McCord, M. C. (1954). Circulation, 9, 801.

, Balchum, O. J., and Gensini, G. (1956). Circulation, 13, 499.

Brandenburg, R. O., and DuShane, J. W. (1956). Proc. Mayo Clin., 31, 509.

Brewer, A. (1953). Proc. Mayo Clin., 28, 480.

Campbell, M., Neill, C., and Suzman, S. (1957). Brit. med. J., 1, 1375. , and Missen, G. A. K. (1957). Brit. Heart. J., 19, 403.

, and Brotmacher, L. (1958). Brit. Heart J., 20, July.

Dexter, L. (1956). Brit. Heart J., 18, 209.

DuShane, J. W., Kirklin, J. W., Patrick, R. T., Donald, D. E., Terry, H. R., Burchell, H. B., and Wood, E. H. (1956). J. Amer. med. Ass., $160,950$.

Edwards, F. R., Farquhar, H. G., Hay, J. D., and Rees, G. J. (1955). Brit. med. J., 11, 1463.

Hamer, N. A. J. (1958). Brit. Heart J., 20, 215.

Leatham, A., and Gray, I. (1956). Brit. Heart J., 18, 193.

Lee, G. de L., and Gimlette, T. M. D. (1957). Brit. med. J., 1, 1278.

Rokitansky, C. (1875). Die Defecte der Scheidewande des Herzens. Vienna.

Silver, A. W., Kirklin, J. W., Ellis, F. H., and Wood, E. H. (1954). Proc. Mayo Clin., 29, 293.

Swan, H. J. C., Burchell, H. B., and Wood, E. H. (1953). Proc. Mayo Clin., 28, 452.

Kirklin, J. W., and Wood, E. H. (1957). Circulation, 16, 54.

Toscano-Barbosa, E., Brandenburg, R. O., and Burchell, H. B. (1956). Proc. Mayo Clin., $31,513$.

Warden, H. E., DeWall, R. A., Cohen, M., Varco, R. L., and Lillehei, C. W. (1957). J. Thor. Surg., 33, 21. 